\title{
Integrating Urban Wind \\ Power in Wellington
}

\section{collin crabbe arci 591}

MArch thesis submission

Dec 2010 


\section{TABLE OF CONTENTS}

Chapter 1- Introduction
1.1- The Problem
1.2- Research Aim
1.3- Proposed Solution
1.4- $\quad$ Scope of Local Potential
1.5- Reference Criteria
1.6- Summary

Chapter 2- Background

2.1- Origins of Wind Power

2.2- Introduction to Wind Energy

2.3- Implementation Issues

2.4- Current National Energy Condition

2.5- Environmental Impact

2.6- Advances in Current Building Design

\section{Chapter 3- Contributing Parameters}

3.1- Overview of Project Issues

3.2- $\quad$ Structural

3.3- Government

3.4- Societal Considerations

3.5- Economic Considerations

3.6- Summary

Chapter 4- Local Conditions

4.1- Current Local Scope of New Buildings

4.2- Local Weather Conditions

4.3- Local Sustainable Practice

4.4- Summary

\section{Chapter 5- Technology}

5.1- Nacelle

5.2- Blades

5.3- Building-Integrated Wind Turbines

5.4- Case Studies

5.5- Summary

Chapter 6- Project Design

6.1- Aim of Project

6.2- $\quad$ Project Pre-Design Considerations

6.3- Landscape Design and Surrounding Urban Context 
6.4- Building Entrance and Ground Floor

6.5- Building Core and Central Stairwell

6.6- Structure

6.7- Exterior Facade System

6.8- Services

6.9- Summary

\section{Chapter 7- Project Results}

7.1- Technology Used

7.2- Local Weather Parameters

7.3- Predicted Energy Requirements

7.4- Predicted Energy Produced

7.5- Overall Environmental Results

7.6- Summary

\section{Chapter 8-Conclusion}

8.1- Environmental Contributions

8.2- Urban Contributions

8.3- Economic Contributions

8.4- Consequential Questions

8.5- Summary

Bibliography 
Chapter 1

Introduction 


\section{1- The Problem}

The degradation of the earth due to waste and its rapid depletion of its natural resources have gained enough momentum to gather the attention of almost every nation on the planet. There is a natural tendency to try and place blame on the causes of climate change or challenge that we are in the process of a global energy crisis. Regardless of who is responsible for our current situation, the petroleum needed to build and power our man made environment is a resource with a fixed quantity and is estimated to be exhausted at the current rate of consumption by 2040 (UK Energy Research Council, 2009). Oil generates 40 percent of the world's commercial energy (UK Energy Research Council, 2009), this means that we need to re-evaluate the way buildings are oil dependent and how they will consume energy in the future. Nature has the capacity to produce energy from several aspects that are completely clean, renewable and infinite. The way forward is to work with nature to maximise a buildings use of natural elements and the energy nature can provide.

A static building by nature can only perform environmentally at a maximum efficiency a minimal amount of time because they cannot adapt to changing weather conditions. The more erratic the weather conditions, the higher these variances in energy efficiency will be. In order to maximise energy efficiency a building must be able to adapt to suit current weather conditions. Ensuring environmental adaptation and the ability to transform nature into energy will allow it to reach its maximum efficiency. Nature is the main factor in all forms of adaptation or evolution, it has the ability to mediate differences and always adapts to fit within its surroundings rather than try and overpower or block out unwanted conditions.

Wind is one of the most powerful elements of nature and is predominately present in Wellington. Wind has helped shape the planet, powered ships to cross oceans and explore the earth, it has allowed plants to spread their seeds and pollinate and powered a large portion of early industry and manufacturing. Wellington has been referred to as the windiest city in the World, although this is a refutable fact Wellington does possess this natural resource in abundance. Some view the wind in Wellington as a negative but it has the ability to produce a large amount of energy if treated and harnessed properly. Locally wind generated electricity is growing and currently accounts for approximately $4 \%$ of New Zealand's consumed energy (New Zealand Wind Energy Association, 2010). Denmark is currently the world leader in wind powered energy production, with wind producing $20 \%$ of the countries electricity (World Wind Energy Association, 2010).

Presently wind produces only $2 \%$ of the global energy consumed but studies have estimated in the future that wind could potentially produce $70 \%$ of the world's energy (World Wind Energy Association, 2010). With the current known oil reserves being approximately 1200 billion barrels and the world consuming 82 million barrels a day, reliance of oil must decrease and shift towards fully renewable sources. The fluctuation of oil prices also threatens countries energy security, in the last 30 years it has gone from $\$ 20$ a barrel up to $\$ 140$ and than back down to $\$ 40$ again in 2008 (Oil Depletion Analysis Centre, 2009). Wind power is completely sustainable, fairly predictable and one incur fixed price to have the turbines designed and constructed. 
Currently the biggest challenges to wind generated power are; the negative aesthetical result of using rural sites for wind farms, the noise wind turbines can produce, and the distance the wind farms are installed from the cities which require the electricity. The wind farms are a step in the right direction, the overall idea simply needs some adjustment. Integrating wind turbines into our cities built environment has the ability to solve most of the issues wind generated power currently faces.

\section{2- Research Aim}

The aim of my research is to show that a wind powered, environmentally responsive, energy producing building can be integrated in Wellington's city centre and produce enough electricity to be economically and environmentally feasible. The building should serve as a positive icon for wind energy and allow a high degree of public interaction to promote and educate the public about the benefits of wind produced energy. With enough energy producing buildings the energy grid can be created directly inside the very cities which require the energy, leaving the picturesque untouched landscapes wind farm free. A building which has the ability to create its own energy also bears the responsibility to maximise its energy efficiency and environmental performance. The building must be environmentally responsive allowing it to respond and adapt to changing weather conditions to maximise performance. The main design goal will be environmental performance, which is the quantity of energy exchanged from external sources required to keep a building at a desirable temperature and allow all of the building's services to operate fully. These include heating and cooling, electrical, plumbing and lighting.

\section{3- Proposed Solution}

The need for wide spread energy management and renewable energy production has become increasing apparent in the building industry and the world in general in the last several years. Global reliance and unrestricted consumption of petroleum based energy products has seen the price of oil and gas rise at exponential rates and driven the oil rich middle east to become a new world power. "The idea that renewable energy is poised for significant growth should not surprise anyone. The potential is so large partly because renewable energy is such a small piece of the energy landscape today. Despite its small size, however, renewables are what is now on the margin, and one of the basic tenets of economics is that what is on the margin is what really matters." (Taub, 2003)

With changes to large scale energy management plans and the decision to produce large scale buildings which employ alternative energy production tailored to local weather conditions, cities can improve their energy efficiency dramatically. Unfortunately integrating energy producing technology can come at a reasonably high initial price, resulting in a calculated pay back period which clients must consider and deem acceptable. A large portion of companies or developers are unwilling to invest in lengthy pay back periods and are building with price rather than environmental performance as the project driver. This severely restricts any advancement as shifts 
from the current standard construction techniques always require research and development which impose significant sums of money. Building projects that have a substantial budget which can facilitate the thorough research, development and testing required for implementing new technology is usually reserved to large companies or government funded projects. Countries which made environmentally focused researched a necessity are responsible for progressing the building industry to where it is today and have reaped the benefits. If all countries put the same effort and resources into building research the world would be a much cleaner more energy efficient place.

There are two ways a building consumes energy; embodied energy, which is the energy used to produce, disassemble and decompose the building itself and the day to day energy the building continually uses to allow the occupants to use the building in a comfortable and productive manner. There are several different ways to reduce the embodied energy of a building but if a large scale building has a long life cycle this portion of overall energy used becomes smaller and smaller. My research will focus on how new technology and incorporating energy producing elements can reduce the second type of energy consumption.

To determine what environmentally focused construction is possible in New Zealand we need to look at the current local and national projects which have been driven by environmental performance.

\section{4- Scope of Local Conditions}

Currently in Wellington there are quite a few larger scale projects in construction or are scheduled to begin within the next couple of years. Recently there have been a few projects which have strived to push environmental performance capabilities, most notably the Meridian Building and the Department of Conservation building.

The Meridian Building's main driver was producing the most energy efficient building from beginning of the project through construction completion and every day use by the company. They implemented an advanced building management system to monitor the weather and adjust the buildings services to adapt and work with the current weather in terms of heating, cooling, ventilation and lighting. They also insisted on several construction actions to minimise the projects carbon footprint, demanding the construction company recycle as much of the waste as possible and use recycled materials wherever available. The overall goal was to use $60 \%$ less energy and $70 \%$ less water than a typical office building, which they believe they have achieved (McDougall, 2009).

The Department of Conservation felt they had an obligation to nature to try and achieve the most environmentally friendly building they could with the existing building they had to work with. They retrofitted an existing downtown building and paid close attention to the environmental impact of every choice that went into the design of the building. Overall the building saves approximately $\$ 105,000$ a year with active chill beam technology, a double layered glass façade and heat pump water heating system. The building was designed with locally sourced and renewable 
materials wherever possible which add some cost, but cut carbon emissions significantly (Department of Conservation, 2007).

Green focused building is still relatively new in New Zealand compared to areas of Europe but there is a great opportunity for Wellington to push the boundaries and expectations of what energy efficient buildings can achieve. The harsh local weather conditions provide the ideal testing ground for building performance and endurance. The New Zealand government advertises the country as clean and green or $100 \%$ pure, this slogan should be enforced and aspired to by the construction industry. There has been a recent movement to achieve these goals along Wellington's water edge with buildings that represent the city in a positive manner to the thousands of tourists and locals who travel through on foot. In a later chapter I will discuss local conditions in more detail.

\section{5- Reference Criteria}

I will be conducting my research on buildings from several different places which will all have their own specific environmental conditions and combination of building systems. The technology I will be incorporating into my project will be available products which will have been previously tested and have proven performance data; this will produce lower costs and realistic energy yields. I will have to quantify the specified building element's performance data and relate it, as best as possible, to local New Zealand weather conditions in order to justify their relevance. This will entitle examination of local weather trends where the building is located and adjusting their data in proportion to match Wellington's conditions. The buildings examined must fulfil a few requirements in order to make them relevant to my research: The buildings must incorporate energy production in order to increase their environmental performance. These elements should be at a scale which even from a distance can be recognised as part of the architectural expression of the building, allowing the building to act as an icon of wind produced energy. The energy generation must be able to adapt to maximise performance and the buildings must strive to be maximise energy efficiency at every level. These conditions will be further explained in Chapter 3.

\section{6- Summary}

I will research and show how incorporating energy producing architecture into future high profile buildings in Wellington can benefit everyone involved; from the daily building user, the building owner and the city. The new buildings will serve as an iconic symbol of dedication to the environment and allow the city to capitalise on the powerful weather conditions which have helped to define its identity. Defining viability will require showing that incorporating energy production can be achieved in projects built to a similar scale in size and budget to other large scale projects in Wellington. The pay back period for incorporating 'green' elements usually defines the economic feasibility of a project and must be take into consideration. 
There is also the possibility that the building could produce an excess of power and add to the power grid resulting in a source of income for the building owner. All of these possibilities add to the probability that energy producing buildings could become the standard of building for the future, where cities would actually produce and house their own power grid. In the next chapter I will discuss the origins of energy production in architecture and give some background as to why people have used it for decades. 
Chapter 2

Background 


\section{1- Origins of Wind Turbines}

The ability to produce energy through the use of wind started in Holland in the $12^{\text {th }}$ century as a post mill, later called a windmill in areas where there wasn't a suitable water source to power a watermill. The use of windmills rescued Holland from the waters that surrounded the country, which lies several feet below sea level. The windmills powered saws to build infrastructure and allowed houses to be built on previously inhabitable land where dikes where built and the land drained. Windmills created a large burst of growth and an iconic symbol of Dutch innovation and landscape. With this innovation came a profound socially economic shift, the ability to process timber and grain, which was at the time was reserved to the extremely wealthy who were able to control the local economy. The windmill spread through Europe quickly and eventually made its way into North America, creating economic growth every where they were installed. The performance of the windmill was increased through allowing larger degrees of freedom, allowing the entire windmill to rotate to face directly into the wind and allowing the blade surface area to adapt (Stokhuyzen, 1963). The greatest improvement came with introduction of gears which allow for a constant energy output. This method of harnessing wind power is still used in basically the same fashion, with improvements in shape of the wind blade and control of friction. The addition of electrical generation came after the war in the 40's when the Dutch started fitting all of their war damaged windmills with electrical devices to keep them turning as a sign of prosperity and national pride, during the times of surplus wind they noticed that the windmills could use these devices to also create electricity(Stokhuyzen, 1963).

\section{2- Introduction to Wind Energy}

The amount of wind energy being produced is growing faster than ever and is finally receiving global recognition for the potential impact wind power can make. The scale of wind turbines has also diversified, ranging from large scale wind farms which contain hundreds of turbines with $30 \mathrm{~m}$ blades, to small single turbine projects for residential use. The International Energy Agency predicts that wind generated energy will account for roughly five percent of global energy by 2050, but has the potential to reach up to 20 percent (International Energy Agency, 2006). Denmark has already achieved this goal and Spain and Portugal are not far behind. Governmental policy is behind the growth of wind energy allocating funding and support for research and installations which focus on reducing $\mathrm{CO}^{2}$ emissions. "North America has recently started devoting significant resources to wind energy, which was the largest contributor to the 36 percent overall growth in 2008" (International Energy Agency, 2006). In 2007 New Zealand produced 937GWh of wind produced energy which is approximately enough energy for 100,000 houses annually (NZ Wind Energy Association, 2010).

The isolation of New Zealand is ideal for decentralized energy systems, where energy is generated local to its users; the largest problem to date had been making these grids dependable and predictable. Turbine technology has now maximised the time that a turbine is productive to almost 97 percent by tailoring the position, gears 
and blades to each specific area and installation. The issue with adding more technology and moving parts are that they all must be maintained and can break, lowering the lifespan of the turbine. The next evolution is a combination grid with several sustainable facets all combining to create a dependable and renewable energy supply.

Advances in wind prediction are making up for inefficiencies due to wind consistency and new battery and storage solutions are maximizing the life time of energy created during excess wind power. As alternative energy solutions evolve and adapt to create the most effective mix of systems based on local weather patterns, the grid system must also adapt to suit. The problem exists in that the grid is currently provided by the large energy providers which have their own methods of generation which have been put in place at great expense. The current system has been created with electricity only going in one direction, out to the customers. The government is the one party which has the ability and the reason to change the way the grid works. There is a large initial cost to adapt the grid to allow for independent electricity input, but the end result is a reliable, efficient and stable energy grid. The focus must be on the advancement of technology to allow and enable private sustainable energy production.

\section{3- Implementation Issues}

The largest opposition to wind turbines is the negative visual and environmental impact that wind farms have on natural areas where they are usually placed. There is a strong case in this argument for the wind turbine installations doing more damage to the natural environments they are trying to protect. There have been efforts to move the wind farms out off shore or as far away from human view as possible. The negative consequence to this solution is the loss of energy directly related to the distance the generated energy must travel and the extra costs for the additional structure needed. The logical step is to bring the power generation to the power consumption. By taking the wind turbines out of the usual location and placing them into the urban fabric you can eliminate the two major issues facing the installation of wind turbines.

Building-integrated wind turbines have started showing up in a few large scale buildings and have been predicting some impressive annual energy yields. The building and turbine are designed with the local wind conditions as the prevailing design driver with maximising environmental performance the main goal. Full integration brings with it some new design issues regarding constant vibration, movement and noise that are quite foreign to the building industry and must be dealt with very carefully.

There are the obvious structural and mechanical issues that arise from integrating large scale turbines into a building, but there are also significant contextual and political issues that have the biggest impact on how easily a project will be allowed to come to fruition. 
The most prominent issue with urban turbines is public safety. These large moving objects have the potential to be quite harmful and safety is always paramount in a building project. Safety during construction and ongoing operation must be insured and back-ups implemented to insure if any failure was to occur the blades or nacelle could not pose any threat to the public in or around the building. Proper planning years of development and regular inspection can lower any safety issues to a minimal amount.

The visual effects of a large turbine are always strongly opposed in rural environments where technology and infrastructure can visually pollute the natural landscape. Urban turbines however, can be placed on or attached to roof tops of large multi story buildings which are rarely seen by the public. Large urban turbines can serve as a distinctive landmark and be used as an icon of a company's environmental integrity.

Noise is an issue that every turbine development must consider and satisfy general noise regulations which can be set by local or nation government. Generally urban regulations permit higher noise levels than rural limits but may not be intended for large turbines. Noise is emitted from a turbine aerodynamically, from the wind passing and pushing on the blades or mechanically from the rotation and friction inside the nacelle. Mechanical noise emission has been cut dramatically through the development of gearboxes and lubricants. The majority of noise from large scale turbines is generated aerodynamically, which was a major factor in the development of the turbine from the common three blade horizontal axis turbine to the newer models which use a vertical axis. The variances in turbines will be discussed in a later chapter.

\section{4- Current National Energy Conditions}

Currently New Zealand uses wind generated energy for $4 \%$ of its total energy consumption which is approximately 500 megawatts of power and are in operation $90 \%$ of the total allowable time. "Hydro generated power is responsible for $57 \%$ of New Zealand energy, gas produces $13 \%$ and coal is still responsible for $10 \%$." (Energy Information and, 2010) The energy production ratio has been created from the abundance of natural energy resources and New Zealand geographical position and global isolation. The government energy policy "has been marked by a commitment to light-handed regulation, to ongoing government monitoring and review and to liberalisation. Its success with energy market liberalisation is remarkable. In fact, New Zealand was a pioneer in electricity market liberalisation, whereas many countries are just starting down the path of liberalisation." (International Energy Association, 2006) Governmental energy policy must be constantly changing to match the energy production market which currently is constantly evolving and becoming more efficient. The problem is that to install any type of energy production infrastructure is incredibly expensive and the technology is improving at such rapid rates that is can become outdated during construction. The solution is to allow and encourage private sector energy production. The government created two regulatory bodies to insure that there would be continual review of its energy markets to ensure efficient and competitive outcomes, the Electricity 
Commission (EC) and the Gas Industry Company (GIC). Compared to most countries New Zealand has high quality and effective energy policy. Renewable energy provides a large percentage of national energy compared to most developed countries, image 02,01 .

Image 2.1

Renewable Energy as a Percentage of Total Primary Energy Supply in IEA Countries, 2004

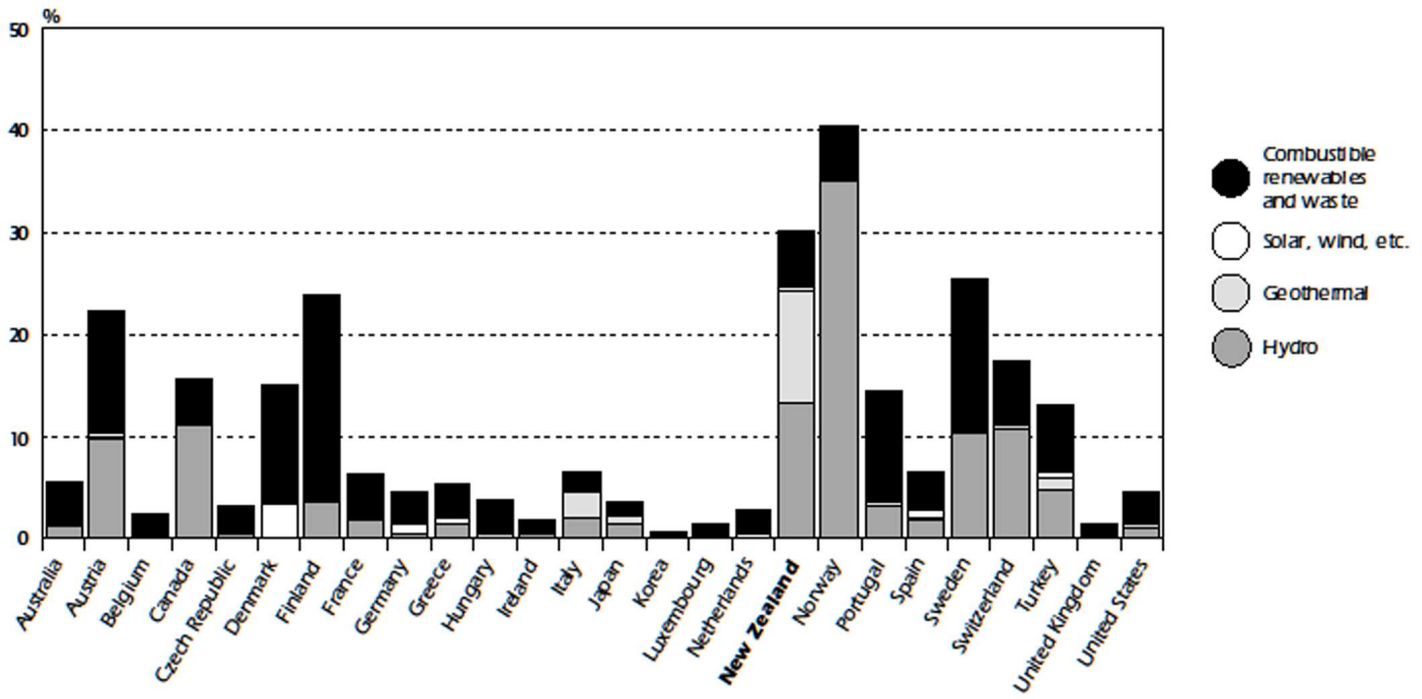

(International Energy Agency, 2006)

The use of wind energy for the production on electricity in New Zealand is relatively new but it is the fastest growing renewable energy resource. There is the issue of intermittency of production due to fluctuating conditions but new technology is reducing this problem quickly with proper gearing and sensing technology. Wind resource is less intermittent in Wellington than most countries but at times can be too powerful and has the ability to damage the grid. One of the overall recommendations the IEA paper concluded was that the government of New Zealand should "Continue to investigate the system effects of greater wind power penetration, such as on grid reliability and stability, and implement appropriate short term and long-term mitigation measures as quickly as possible." (International Energy Agency, 2006) There are currently 12 wind farms operating in New Zealand with another 20 which have either been granted resource consent or are in the planning process. These will be able to contribute up to an additional 3,000 MegaWatts which would increase New Zealand's overall wind energy production $600 \%$ and could provide $25 \%$ of New Zealand's overall energy. (NZ Wind Energy Association, 2010) In 2008 the New Zealand Wind Integration Study was conducted which concluded that while wind energy should continue to grow at a fast rate, image 02.02, that it must develop an infrastructure which develops the wind system to work simultaneously with its hydro system (Strbac, 2008). This combination of systems should be able to produce an energy system which can balance out each others low periods and operate at a near constant level and produce highly predictable outputs. 
Image 2.2

\section{Summary of Key Results}

\begin{tabular}{|l|c|c|c|}
\hline & 2010 & 2020 & 2030 \\
\hline Installed wind power capacity (MW) & 634 & 2,066 & 3,412 \\
\hline Wind power (GWh) & 2,285 & 6,724 & 10,797 \\
\hline Capacity credit of wind (\%) & 32 & 29 & 15 \\
\hline Max. Instantaneous Reserve (MW) & 565 & 691 & 912 \\
\hline Max. Frequency Keeping (MW) & 309 & 540 & 866 \\
\hline Max. Standing Reserve (MW) & 46 & 377 & 566 \\
\hline Capacity cost (\$/MWh of wind) & $1.7-2.5$ & $1.3-2.0$ & $6.2-9.3$ \\
\hline Reserve cost (\$/MWh of wind) & 0.19 & 0.76 & 2.42 \\
\hline $\begin{array}{l}\text { Total cost attributed to wind } \\
\text { (\$/MWh of wind) }\end{array}$ & & & \\
\hline
\end{tabular}

(NZ Wind Energy Association, 2010)

\section{5- Environmental Impact}

The New Zealand government released its first defined energy efficiency guidelines in 2001 with the National Energy Efficiency and Conservation Strategy or NEECS. This was to promote nation wide energy protocol for energy efficiency, renewable energy resources and to "move New Zealand towards a sustainable energy future." (International Energy Agency, 2006) This is to be reviewed every 5 years and targeted five main areas: government, energy supply, industry, buildings and transport. The Electricity Commission is responsible for improving energy efficiency in New Zealand and funding energy efficient directed projects from funds which are collected from a levy on sold electricity. The Ministry of Economic Development estimates that by 2025 wind farms could generate up to $2500 \mathrm{GWh} / \mathrm{yr}$, enough for 312,000 New Zealand households.

Wind power while relatively unpredictable has the overlying benefit, once constructed, of being able to produce electricity without emitting any carbon dioxide, "The lifecycle emissions (including manufacturing of components, construction, operation and decommissioning) from wind farms are about $1 \%$ of emissions from thermal generation." (NZ Wind Energy Association, 2010)

Wind farms can have quite a negative effect, damaging natural habitats and vegetation. Extensive site analysis is carried out to try and minimise environmental damage although some damage is inevitable, approximately 1-3\% of a wind farm site is destroyed to construct the turbines and access roads. The debate lies in if this is an acceptable margin. 


\section{6- Advances in Current Building Design}

There is an alternative placement strategy which can eliminate the need for natural, exposed landscapes. Building integrated wind turbines or BIWT have opened up an entirely new direction for wind turbine technology. Installing turbines directly in or on top of buildings designed with wind specific aerodynamics has created a new type of environmental focused development. There are a few examples of new medium to large scale commercial buildings which have integrated turbines and several more are currently under construction. The World Trade Centre in Bahrain was completed in 2008 and designed by Atkins.(image 2.4) It was the first large scale building integrated project completed and houses three $29 \mathrm{~m}$ horizontal axis turbine surrounded by two wind accelerating towers. The tapered design resulted from thorough wind tunnel testing and computational fluid dynamic which allowed all three turbines, regardless of elevation, to produce equal amounts of electricity. The turbines resulted in less than $3.5 \%$ of the project value but will produce up to 2000MWh per year, enough for 10,000 $\mathrm{m}^{2}$ of office space (Bahrain World Trade Center, 2009). Aerodynamically driven building design has also been used extensively for natural ventilation purposes, including Norman Foster's famed "Gherkin" (image 2.5) at 30 St. Mary Ave, London by creating high and low pressure systems over curved building facades.

Image 2.4



(Bahrain World Trade Center, 2009) 


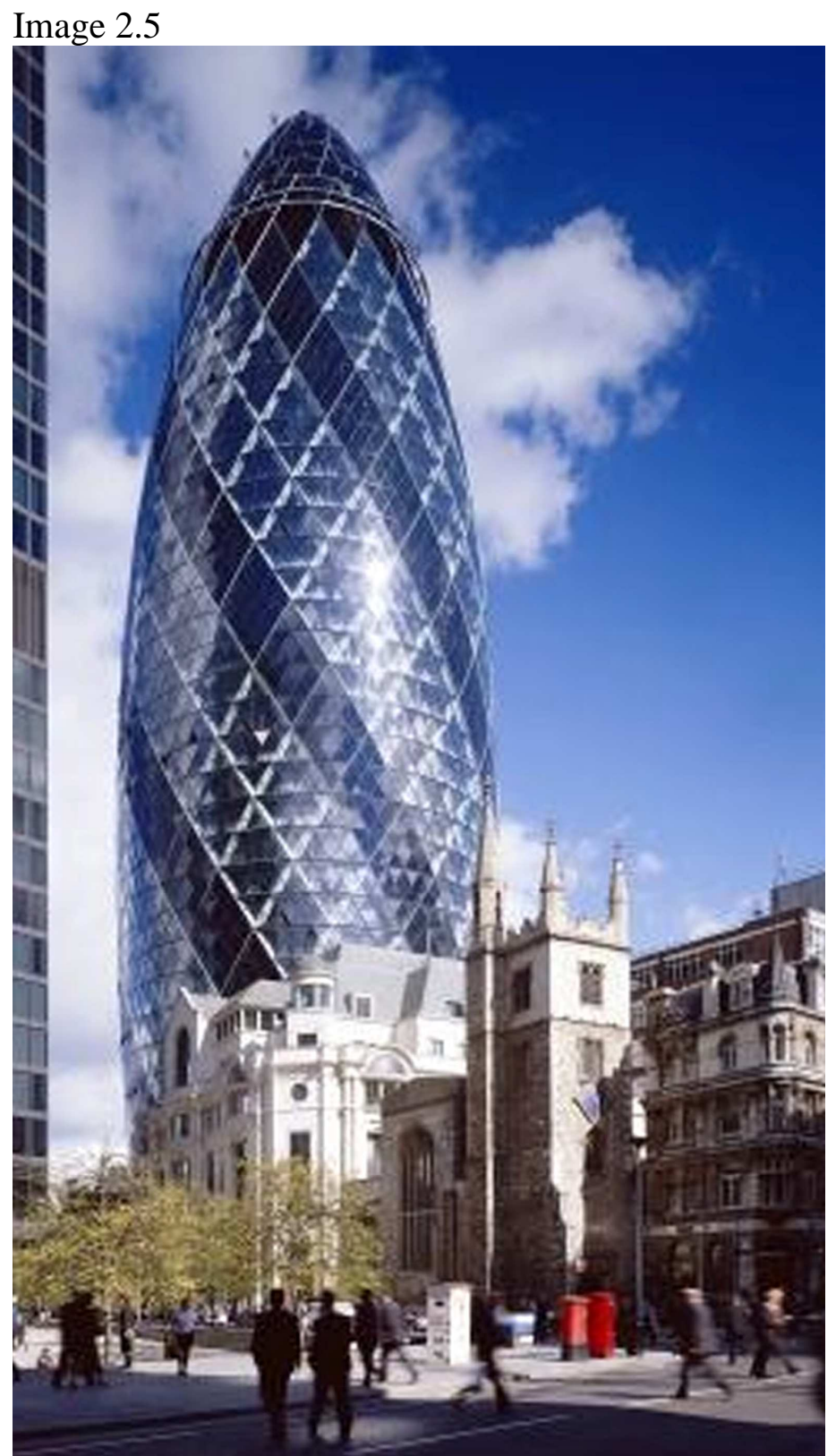

(30 St Mary Axe, 2008) 


\section{Chapter 3}

\section{Contributing Parameters}




\section{$\underline{3.1-\text { Overview of project issues }}$}

Introducing a foreign object into a well established and defined entity has always been met with opposition and resistance. The few existing building integrated wind turbines that have been finished or are in the construction process all had to overcome issues from several aspects of the consent and construction. There are some obvious and essential issues with the large moving blades that must be scrutinized over to ensure public safety. There are structural issues with the vibration caused by the turbines and certain turbines can create high levels of noise. These are all technical issues that can be solved with thorough design and collaboration between architects and engineers. The largest opposition comes from the social, economical and urban aspects that can affect large scale urban projects. Changing the way a building operates as a part of the city and possibly reversing the flow of electricity often requires exceptions from design guides and building standards due to the irregular and untraditional shape and appearance of building integrated wind turbines. The changes and exemptions usually require some form of government granted exemptions, this requires a government which is willing to be environmentally innovative and encourage the building industry to evolve.

\section{$\underline{3.2-\text { Structural }}$}

The loads associated with a moving turbine can be quite foreign to the usual load calculations and have proven to be a problem with current built examples of turbine integrated buildings. The three turbines in the Bahrain World Trade Centre had to be shut down temporarily to re-strengthen and adjust the structure due to softening and deformation of the structure. The constant movement of the turbines cause the metal and concrete to deform over time. While the deformation increases the stress on the structure decreases but continues to cause further deformation which will eventually lead to failure. (Stankovic, 2009) There have been advancements in structural isolation borrowing some solutions from earthquake technology to allow the vibration caused by the turbine movement to be absorbed before it reaches the load bearing elements. The "use of finite-element stress codes are now routinely used to ensure so that key components can withstand the huge loads placed on them by weight, motion and 50-year-return wind speeds." (Stankovic, 2009) There are a variety of suspension options to support the blade and nacelle portion of the turbine and each have aerodynamic and vibration implications, the most common are: a simple tower, a full length vertical or horizontal support and tension suspension rods or wires. All of the structural issues must be addressed and analysed properly during the initial design stage so that the building and turbine can work together. The structural issues are usually the easiest obstacles to overcome. 


\section{3- Government}

The governmental issues vary quite significantly depending on country, some are more than willing to allow or even help fund experimental energy efficient buildings. Other governments forcefully oppose any progressive or experimental technologies and oppose any private energy feeds into the national grid. Several European countries have deposited great amounts of resources in alternative energy research and offer large feed in incentives. In the United Kingdom new high rise buildings are now required to use renewable energy for $10 \%$ of the overall electricity consumption. The new EU Energy Performance of Building Directives law also requires an alternative energy feasibility study done for all new buildings over $1000 \mathrm{~m}^{2}$. (International Energy Agency, 2007)

In 2006 the Ministry of Economic Development of New Zealand published 'Powering Our Future - Towards a sustainable low emissions energy system' a paper to get appropriate parties together to determine and define New Zealand's best policy approach towards public alternative energy production, energy feed in tariffs and carbon credit accreditation and trading. The paper states that carbon credit trading schemes in Europe on their own have proven to be somewhat ineffective, expensive and often more about bureaucracy. It recommends that the most cost effective and efficient strategy is government feed-in tariffs for private energy generation. The paper recommends that New Zealand use Germany and Thailand's energy feed in guidelines and that it will greatly benefit all parties involved. (Ministry of Economic Development, 2006)

Public energy feed in increases national grid stability, reduces the cost of electricity production and will benefit industry that is located away from major cities, such as farming, the most. Public energy production uses existing technology and an already installed infrastructure so it can almost instantly be up and running. The other major benefit is that feed in tariffs promote local companies to invent and produce a variety of energy conversion technology in a range of scales. Although solar and wind power would produce the greatest amount of attention, other forms of alternative energy would get a new life of research. New Zealand has an extremely large potential for Bio-fuel energy production. The farming industry produces a significant amount of animal waste which produces heat naturally and can be treated and cleanly burned. (Ministry of Economic Development, 2006) There is little public resource available for the advancement of this technology unless public energy feed in is allowed and promoted. Another large New Zealand industry that produces a large amount of waste that has the ability to be burned cleanly is timber processing. There is a significant amount of cut off and waste which can be converted to energy. All of these processes can be currently set up, but the infrastructure required and technology available for a self sufficient electricity production and storage is still quite inefficient and economically unfeasible. EECA currently offers grants for alternative energy projects although most of the technology is still so expensive it excludes most small scale projects. Although New Zealand is still behind several European countries in sustainable energy production things are beginning to move in a new direction. 


\subsection{Societal Considerations}

The effectiveness of wind energy generation depends on being close enough to the city centres to minimise the cost of infrastructure and maximise potential electricity yields, while still being located in an exposed environment with optimal wind exposure and speed. This combination requires an exposed natural environment close to a city which will be visible to the surrounding population.

The main societal stigmas attached to alternative energy are the visual changes, which are usually in pristine natural landscape. Wind farms attract the most amount of negative attention in New Zealand as most of the solar power panels are usually placed on roof tops and are usually smaller set ups, although in some countries they do construct large sun farms with thousands of solar panels. The negative press is usually created by a minority of people, surveys in New Zealand have been conducted on public conception of wind farms and recently shown that "77\% of respondents said they prefer wind as the best energy source in the next decade and $48 \%$ said they like the way wind farms look, while $44 \%$ say it depends on where they are located." (Shape NZ, 2008) Public popularity for wind energy is increasing every year affected directly by the amount of media coverage expressing the environmental damage to the earth, yet $70 \%$ of New Zealanders still feel the government is not doing enough to encourage renewable energy projects.

The introduction of BIWT has the ability to solve both social problems of requiring clean energy production and protection of natural rural areas. The main social issues of BIWT have been with public safety and noise pollution, both of which are being targeted with research and advances in technology.

\section{$\underline{3.5 \text { Economic Considerations }}$}

The economics of a wind based project is directly linked to the conversion of wind energy to electricity, which determines the success or feasibility of a project. Electricity output is directly linked to either money saved or earned and although using wind is much cleaner and environmentally responsible than conventional electricity generation methods, if a project will cost more than it will earn it will rarely be built.

The New Zealand Wind Energy Association currently states that wind energy currently costs approximately from $\$ 80$ to $\$ 120$ per megawatt hour to produce; this includes land cost, equipment cost, yearly maintenance and connecting the transmission lines. Unfortunately wind farms in New Zealand do not currently receive any government subsidies so developers must be able to produce electricity at a competitive price to all other methods of generation. Wind energy is becoming a more competitive option for electricity generation as the cost of thermal energy is increasing with the introduction of fees on greenhouse gas emissions. Coal is rising in price with carbon emissions tax and the cost of natural gas is also rising, which is used in a large part of the rural areas in New Zealand. All of these factors will 
contribute to raise electricity prices $\$ 15$ to $\$ 25$ per megawatt hour in the next few years. (NZ Wind Energy Association, 2010) Wind power production costs will most likely actually decrease in the future with "mass production supplemented by design improvements and industry maturity" (Energy Research Unit, 2005). The New Zealand Wind Integration Study in 2008 states that the cost of integrating large scale wind energy into the existing electricity system is much lower here than in Europe or other areas because of the extensive wind resources and established hydro generation in New Zealand. With a larger portfolio of electricity options spot prices will be reduced almost immediately, with thermal generated energy becoming too expensive to produce to compete with wind power. The added security during dry years will also lower consumer prices with a reduction of dependence on hydro electricity (Strbac, 2008). In Denmark, thanks to their world leading wind power industry, their electricity prices "would have been approximately 7 to $13 \%$ higher in 2005 if wind power had not made such a contribution. This translates into a saving of 0.3 to 0.5 €cents per kWh consumed." (NZ Wind Energy Association, 2010) It appears that all economic studies favour a large growth of wind power generation in New Zealand over all scales of production and that not only is it economically feasible now it appears the start up costs will actually decrease in the future.

The economics of developing a BIWT building is no different from all wind energy projects, its production versus price. Payback period is quite often the defining point of alternative energy project, unfortunately environmental performance usually comes second.

\section{$\underline{3.6-\text { Summary }}$}

As with all technological shifts in construction, obstacles will occur in every aspect of a project and must be anticipated with proper planning and research. The end result of a reliable nation wide energy grid based on clean sustainable production will ensure a solid future independent from the certain depletion of the earth's oil and gas reserves. The powerful and relatively predictable wind conditions matched with a small population and isolation from other countries make New Zealand the perfect country to test the limits of wind generated electricity production. In the next chapter I will discuss the local conditions and feasibility for developing a building integrated wind turbine project in Wellington. 
Chapter 4

Local Conditions 


\section{$\underline{4.1 \text { - Current local scope of new buildings }}$}

There have been quite a few medium to high rise buildings built in Wellington over the last few years, several of which along the waterfront in a move to reinvigorate the area. The major projects in Wellington over the last few years have been in the $\$ 100$ to $\$ 150$ million dollar range, with commercial space being built for approximately $\$ 2500$ to $\$ 3000$ per square metre. There has been a shift towards producing more environmentally friendly buildings with several of the new buildings built along the waterfront by the CentrePort corporation, along with the new Telecom building that have received a 5 star environmental rating. Developers are starting to see the advantages of offering environmentally efficient buildings, commercial office space can use up $350 \mathrm{kWh}$ per $\mathrm{m}^{2}$ annually and tenants are willing to pay higher rent in efficient buildings. There is also the positive public view and opinion of the companies who occupy these buildings. There is prediction that the local construction industry will slow down post 2011 Rugby World Cup, although there are several other large scale projects in development on, or adjacent to the Wellington waterfront.

\section{$\underline{4.2-\text { Local weather conditions }}$}

The one element that defines Wellington is wind and is known globally for its powerful gusts. Geography amplifies these conditions, "Wellington is located next to Cook Strait, which forms a narrow gap between the mountain ranges of the North and South Islands. This gap between the islands and mountain ranges accelerates the wind through the Cook Strait making Wellington a very windy city." (Te Ara, 2010) Wellington has a monthly mean average wind speed of $24 \mathrm{~km} / \mathrm{h}$ to $36 \mathrm{~km} / \mathrm{h}$ with Northerlies being the most frequent wind direction, blowing $61 \%$ of the time, followed by southerlies which blow $28 \%$. This graph shows the average wind direction and speed in knots (image 4.1) and how Wellington compares to the rest of New Zealand (image 4.2). The predominately axial wind conditions allow the turbines to focused in a small directional range, improving energy output and saving money.

It's not necessarily the average wind speed which separates in from other cities, it's the powerful gusts, Wellington gets up to 173 days a year with gusts of $60 \mathrm{~km} / \mathrm{h}$ or more. (Te Ara, 2010) The constant wind which fluctuates in speed and strength provide the perfect location to implement and test the possibilities and limitations of a BIWT building.

\section{$\underline{4.3 \text { - Local sustainable practice }}$}

The construction industry consumes $1 / 3$ of the world's energy and produces $40 \%$ of its waste (Keys, 2010); these facts come with a lot of responsibility and a lot of room for improvement. There are several factors that contribute to make a project as environmentally friendly as possible: energy efficiency, waste reduction, carbon 
emissions, product and material selection, etc. There are several ways to minimise the damage, Green Star has developed tools to quantify waste reduction in New Zealand. The star rating system which has been adopted to measure the environment success of a project is a "comprehensive, national, voluntary environmental rating scheme that evaluates the environmental attributes and performance of New Zealand's buildings using a suite of rating tool kits developed to be applicable to each building type and function." (Green Star, 2008)(Green Star) The rating system evaluates buildings under nine criteria points: management, indoor environment quality, energy, transport, water, materials, land use and ecology and emissions and awards them either a four, five or six star rating. There are only two buildings in New Zealand which have ever been awarded a six star rating, the latest being the Christchurch Civic Building which will save an estimated \$1.3 million a year in energy. Green Star was launched three years ago and a sign the things are improving in New Zealand, NZGBC Chief Executive Jane Henley states "There's a sea change occurring in the way the industry considers how buildings should be designed and built, and what we're seeing in Christchurch is a prime example." (Green Star, 2008) Wellington currently has several 5 star buildings, with 3 almost side by side along the waterfront.

The energy portion of the Green Star rating has the majority of its points awarded to sensors and metering which allow proper control and monitoring of the lighting, heating and air exchange. Building management technology allows a building to only use what is necessary and provide the proper conditions only to specific areas of a building which are being used.

Designing a building which produces its own energy must also focus on being as environmentally efficient as possible or the energy production may simply become ornamentation.

\section{$\underline{4.4-\text { Summary }}$}

New Zealand still has a large problem with inefficient buildings that have extremely poor insulation, leak water and were built to an overall low quality. The best solution is to rethink how buildings are produced here, to look at other regions which have been producing sound structures which can cope and thrive in environments as extreme as New Zealand. The best way forward is to not repeat the same mistakes and to develop New Zealand's own building industry to produce its own sustainable practice and products. The people inside the industry must promote building performance and endurance rather than speed and price as the project design drivers.

Buildings which incorporate wind turbines require more initial design time to coordinate all the environmental and societal impacts. These issues will vary significantly from site to site and must be assessed and addressed independently to allow for maximum performance. Thorough planning and technology are the main contributors to a successful wind energy project. I will discuss the current BIWT technology options available in the next chapter. 
Image 4.1

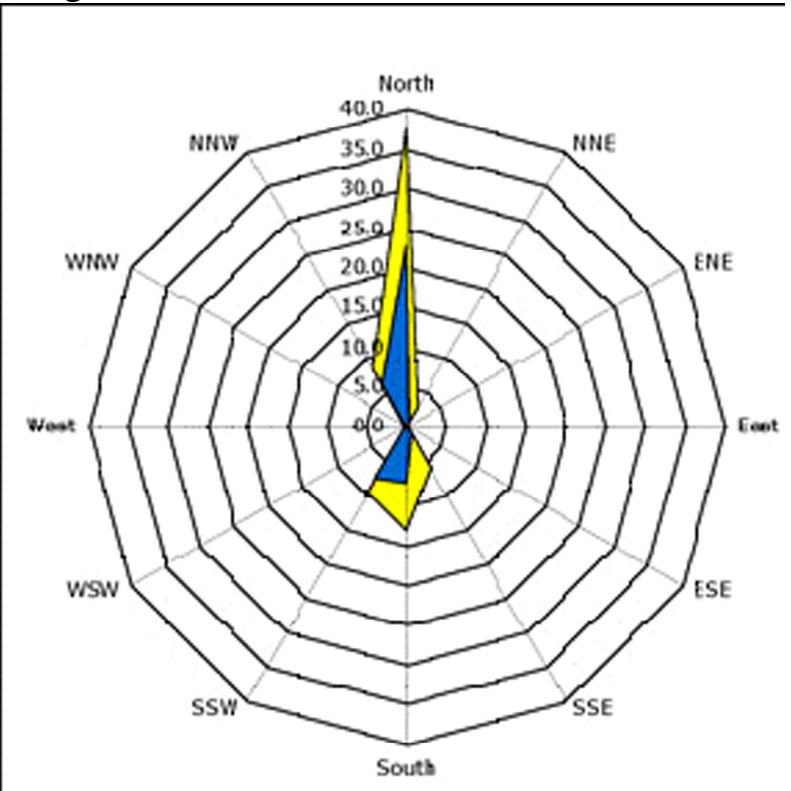

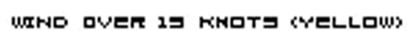

RND QVER 20 KNDTS (BLUE)

WINO DIRECTION FND SPEED FOR WELLINGTON RIRPURT

(Te Ara, 2010)

Image 4.2

\begin{tabular}{|c|c|c|}
\hline Lecatien & $\begin{array}{l}\text { Wind atigan } \\
\text { spend } x \mathrm{~m} \text {. }\end{array}$ & $\begin{array}{l}\text { Calin days, masit } \\
\text { spesd at ipast flymb }\end{array}$ \\
\hline Ranes & +1 & 2 \\
\hline WWHNesha: & 7 & \pm \\
\hline MCKEASO & 17 & $\frac{1}{2}$ \\
\hline 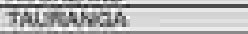 & the & है \\
\hline Fonetifar & HI & 3 \\
\hline ADtrave & 五 & I \\
\hline 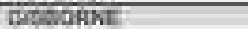 & t5 & $\frac{5}{2}$ \\
\hline $7 \mathrm{THOO}$ & in & $\frac{7}{2}$ \\
\hline Fil:Wr-mooumil & 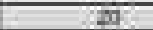 & $\pi$ \\
\hline DिसE & 7 & 3 \\
\hline Makcotin: & 78 & 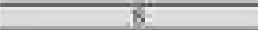 \\
\hline PRWE- & in & 3 \\
\hline 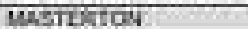 & It: & T \\
\hline WELIMOTOW & 25 & 22 \\
\hline FLSOW & 72 & 2 \\
\hline 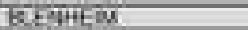 & $\pi$ & $\frac{\vec{i}}{i}$ \\
\hline Wharpion? & if & 2 \\
\hline kaxpejh & 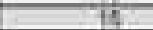 & N \\
\hline IFOWTik.h & in & 2 \\
\hline 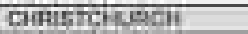 & 75 & 3 \\
\hline Wrogos & tit & T \\
\hline Was TENANS & $y^{11}$ & 1 \\
\hline mingil & id & 6 \\
\hline Widpasacos & 晋 & $\frac{\pi}{8}$ \\
\hline 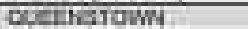 & $\frac{12}{12}$ & 2 \\
\hline 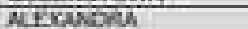 & $\mathrm{c}$ & 3 \\
\hline 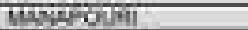 & 70 &  \\
\hline DOto:Der & 晋 & h \\
\hline  & 78 & II \\
\hline  & 21 & TiL \\
\hline SOOTIRES & 21 & it \\
\hline
\end{tabular}

(NZ Wind Energy Association, 2010) 


\section{Chapter 5}

Technology 


\section{$\underline{5.1-\text { Turbine types }}$}

There are two types of turbines, vertical axis and horizontal axis wind turbines (VAWT and HAWT). The VAWT (image 5.1) is a much newer technology that has produced several products in the small to mid range field and have become more popular in this range but has yet to make a real impact in the large scale turbine market. They both have their advantages and disadvantages and both have progressed significantly with the recent expansion of turbine produced electricity.

The VAWT requires less maintenance due to the blades being in a fixed position and having fewer, slower moving parts. Having fixed blades means the outer shell of the turbine needs fewer openings and allows less debris or dust to enter inside the turbine, resulting in less maintenance costs. There is much less noise produced from the VAWT because the blades spin at a slower rate and are a fixed curve rather than the traditional blade tip. The VAWT perform very well in indirect and swirling winds, HAWT are much more efficient in wind from a constant horizontal direction. One of the negatives are the VAWT are typically slightly more expensive due to it being relatively new technology.

All of the recent large scale BIWT projects have used a classic three bladed VAWT (image 5.2) which is also used in wind farms. This typical configuration has been proven to have a high output capacity in high speed conditions but do not perform very well in low wind speeds. The large scale HAWT can produce a large amount of noise, which may limit their use in an urban environment if not installed properly.

\section{Image 5.1}




Image 5.2

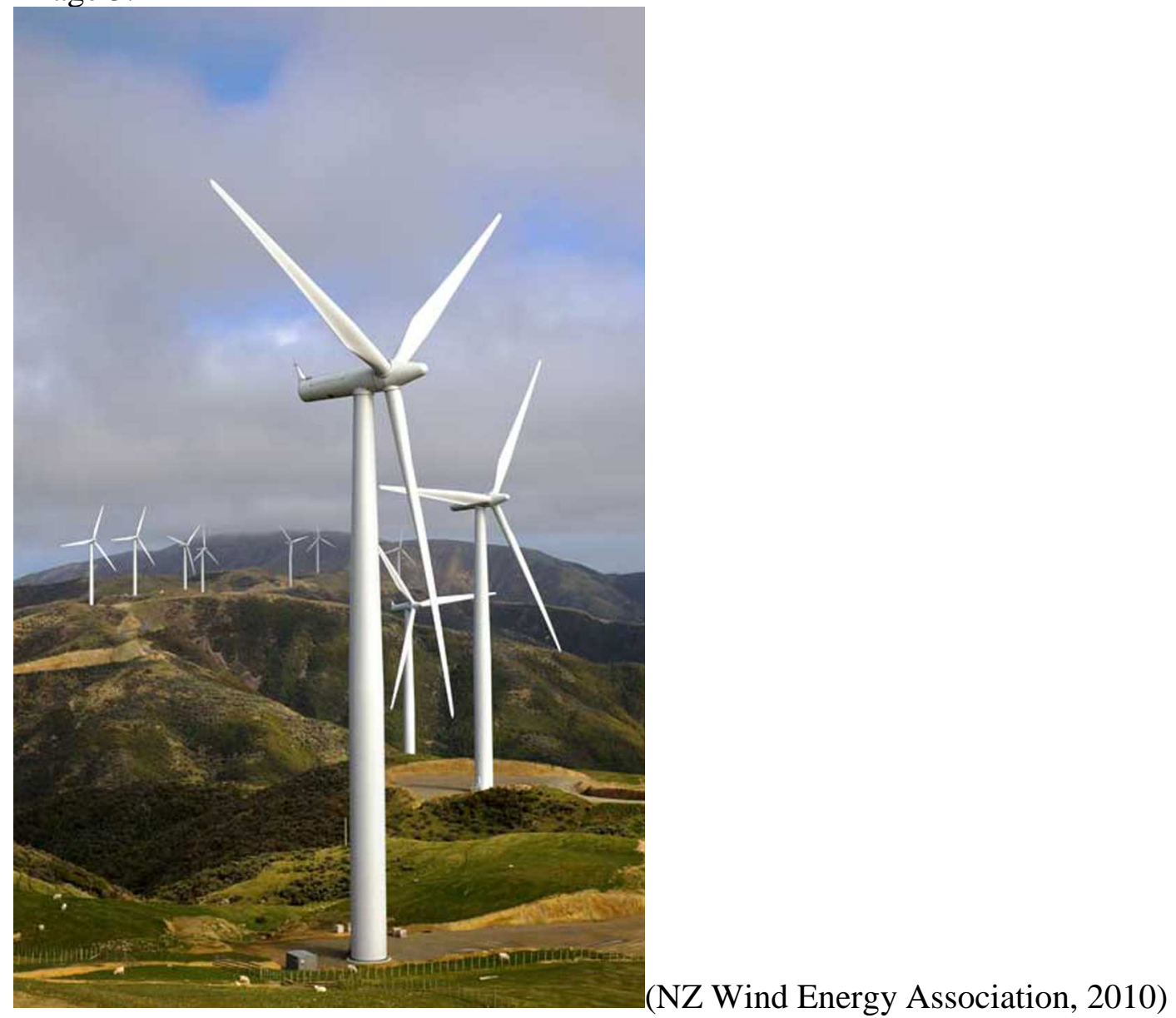

\section{2 - Blades}

Both VAWT and HAWT use one of two forces to drive the turbine blades, either drag or lift force (image 5.3). Traditional HAWTs use drag force, these were larger windmill type turbines and their speed is governed by the speed of the wind. All modern turbines use lift force, which allows for faster moving blades with smaller surface areas.

The majority of VAWTs use lift force as it has a higher output of energy per meter squared of swept area. There are certain areas of application for drag powered VAWTs, as they have different positive attributes that can be very useful in certain areas. Drag powered VAWTs can operate in higher wind speeds and more extreme climates as they are usually constructed quite heavy and robust, are low maintenance, start to operate at low speed and are typically very quiet. (Stankovic, 2009) They perform well at low speeds but are not that efficient at high wind speeds, the result is usually a higher payback period. Currently the most common VAWT are the Darrieus turbine (image 5.4) and the triple helix diagram (image 5.1). The Darrieus turbine has been trialled in wind farm applications and in theory can be as effective as a traditional three bladed HAWT but have proven to have structural and resonance issues due to the changes in torque during rotation due to its flow mechanics (image 5.5). Due to these issues any attempts to implement a Darrieus turbine into a building structure has caused structural damage to the building. The triple bladed helix has proven to be a popular option and is continually increasing its share of the 
turbine market. They have the least amount of noise and vibration emitted allowing it to be used extensively in urban installations. It has also proven to be the most aesthetically pleasing turbine in an urban environment. (Quiet Revolution, 2010)

\section{Image 5.3}

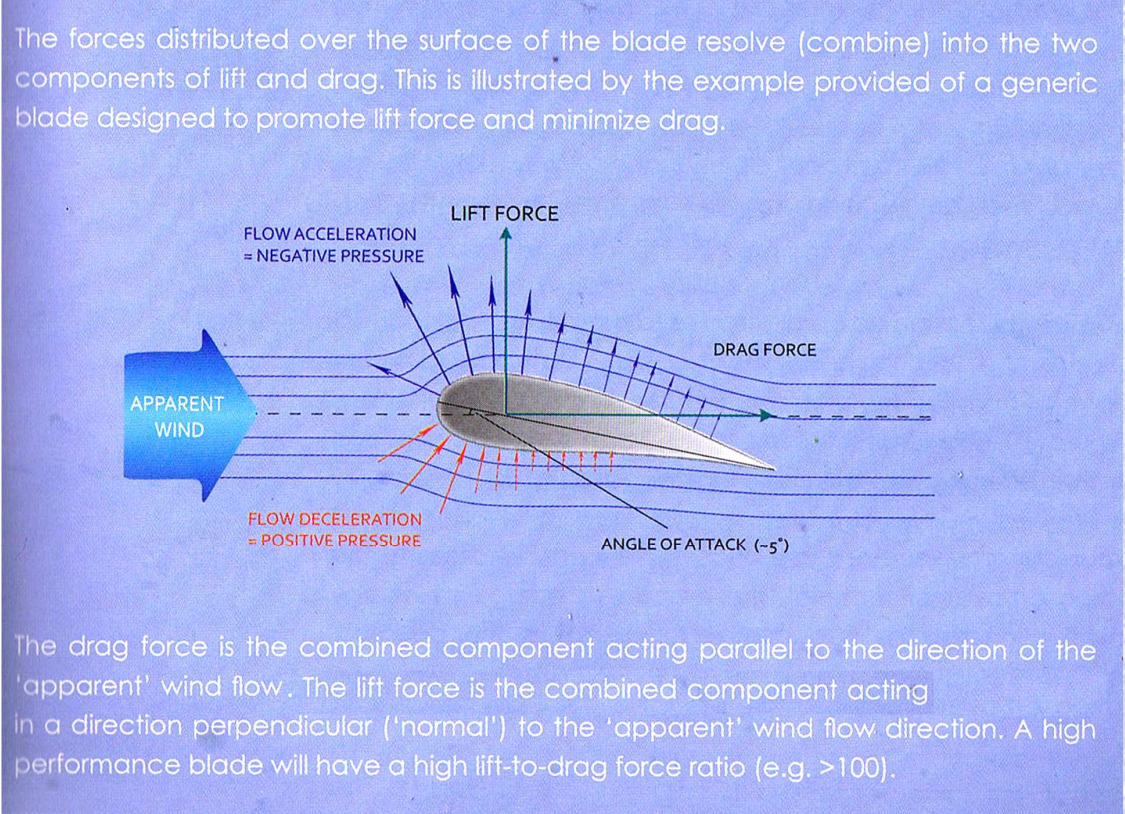

(Stankovic, 2009)

\section{Image 5.4}

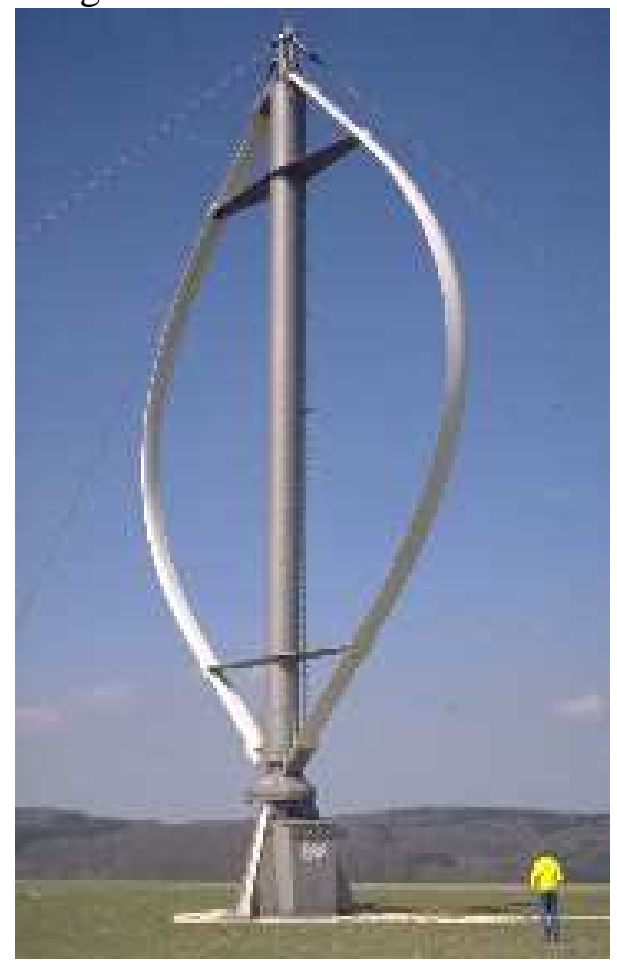

(Reuk, 2010) 
Image 5.5

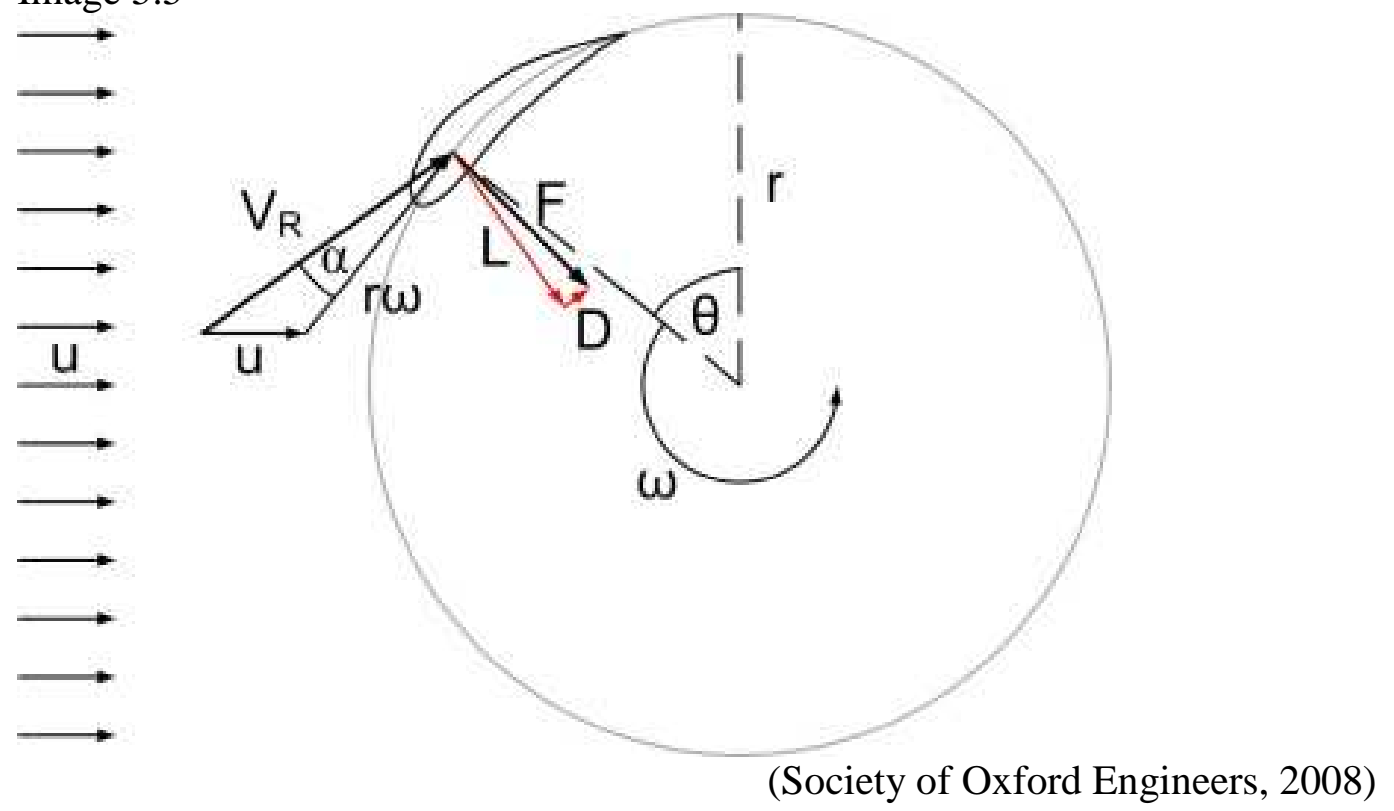

\section{$\underline{5.3 \text { - Building Integrated Wind Turbines }}$}

These buildings represent a new direction in environmentally focused architecture by visually emphasizing the buildings ability to generate its own electricity and celebrate the aesthetic values of a turbine. The buildings are designed specifically for wind energy with aerodynamics the dominant design driver in all facets of the project. In order for a building to produce enough electricity to be viable it must use a large scale turbine which can cause significant problems, it can produce a significant amount of noise and vibration to the surrounding area and the building itself. There are several issues that are amplified when designing a BIWT; orientation, vibration, acoustics, façade construction, ventilation, safety features, electrical services and most notably the structure. The design of the project will take much longer and will involve more specialists due to the amplified environmental requirements of a project. Than also add on the design and incorporation of a large moving turbine and all the extra planning and consent which will extend the preconstruction time even further.

The first step in the design is to review the wind conditions available for the site and find the optimum orientation and vertical placement of the turbine through a thorough and extensive wind study. In an urban environment this usually requires elevating the turbine to get access to the largest amount of uninterrupted wind flow which will provide the fastest and most powerful winds. The next step is to evaluate any constraints the site may have and if there are any possibilities to accelerate wind speed with the shape of the building. After the required turbine position and building shape is determined the building structure and occupant comfort must be ensured, including any ground level pedestrians. In an urban environment the air pressure of the surrounding area can be affected, especially when buildings are designed to accelerate the natural speed of the wind. This change in pressure can effect the surrounding buildings and can even help with natural ventilation if dealt with properly. There must be extra caution during the design period to ensure there are not systems 
working against each other or that implementation of the turbine causes the building to use excess electricity.

Ideally a BIWT should utilize existing turbine technology to control costs, although the new turbine support structure must be specially designed to insure complete safety during any type of failure or earthquake. Any turbine structure will block a certain portion of the incoming wind, so the smaller the better, but it must also be able to dissipate any resonance from the rotating turbine.

\section{$\underline{5.4-\text { Case Studies }}$}

There have been only a few large scale BIWT projects completed and have all experienced some problems in reaching a functional state. There have also been several extensive experiments to test the different configuration options and maximum yields possible from a BIWT.

Project WEB was an experiment focused solely on BIWT, it was conducted over two years and concluded in September 2000. It included architects, planners, environmental, mechanical and structural engineers and aerodynamicists that where practitioners and academics from different parts of Europe. The project "has been the development and demonstration of wind enhancement and integration techniques, which improve the annual energy yield per installation by concentrating the low to moderate wind speeds $(2-5 \mathrm{~m} / \mathrm{s})$ typical of most urban areas in Europe. This has involved balancing and reconciling aesthetic, aerodynamic, architectural, environmental and structural constraints." (Project WEB Partners, 2001) They researched the full integration of wind turbines driving the architectural form (image 5.6), how to deal with the issues of turbines being located close to other people and property and how wind acts in an urban environment. The first stage of the research looked at the aerodynamic properties of a building and how these could enhance wind speeds. A typical windmill or turbine has the ability to rotate to face directly towards the wind, or yaw, a high performance building should be able to redirect the wind since the turbine in a fully integrated project must usually remain in a fixed position. Project WEB used wind tunnel testing, flow visualisation techniques of models and ran computer generated computational fluid dynamic testing to try and find the optimal shape for the widest range of wind direction and wind amplification. The testing showed that round smooth buildings with a circular ducted area which tapered around the spinning turbine performed the best. This shape had the best ability to enhance wind speeds and allowed for angles of incidence up to $50^{\circ}$. (Project Web Partners, 2001) The optimal aerodynamic design did however produce some issues architecturally. The resulting towers had a rather deep floor plate which would require artificial lighting and the area surrounding the turbine would have issues of noise, vibration and electromagnetic interference. These spaces should be used as plant rooms and possibly circulation or buffer areas. The project team built a 1/7 scale model and found that placing the turbine inside the ducted section of the building the turbine would produce considerably more power, approximately $25 \%$, than if it was conventionally placed on the same site at the same height. (Project Web Partners, 2001) The research project also produced a project progression chart (image 5.7), it states that a project has feasibility if "there is sufficient wind at the site and no serious 
planning or environmental restrictions. Ultimately, if the project makes technical and economical sense and the environmental impacts are acceptable, planning permission will be granted." (Project Web Partners, 2001)

\section{Image 5.6}

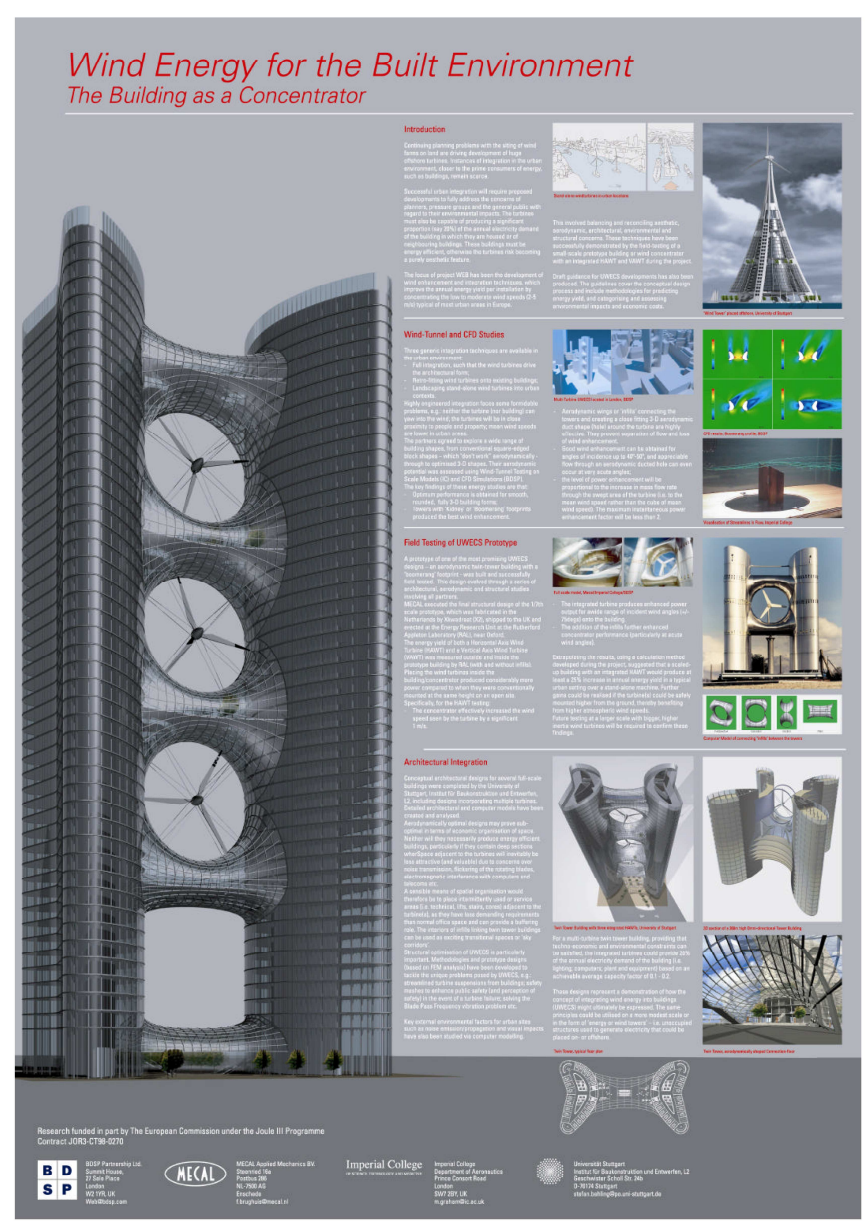

(Project Web Partners, 2001) 
Image 5.7

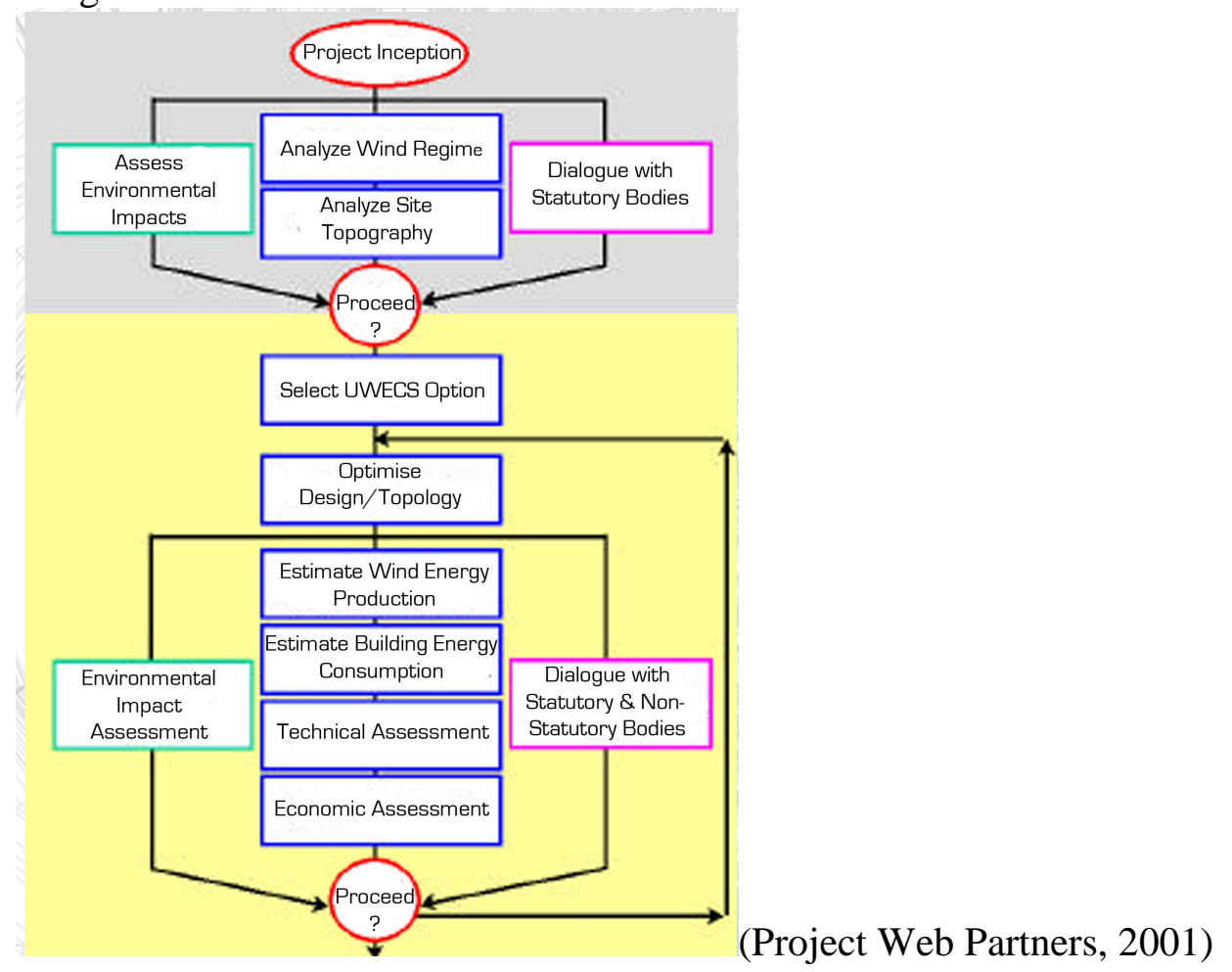

The first large scale completed project was the Bahrain World Trade Centre (image 2.4) which was completed in 2008 is comprised of two $240 \mathrm{~m}$ high towers and three $29 \mathrm{~m}, 225 \mathrm{~kW}$ turbines. The project was done by Atkins at a cost of $\$ 150$ million US, it has 50 stories and its turbines generate up to $1.3 \mathrm{GWh}$ a year which is $15 \%$ of the buildings annual electricity usage. (Bahrain World Trade Center, 2009) The buildings shape was derived using airflow dynamics to accelerate the wind flow both horizontally and vertically. The vertically tapered designed twin towers allow each of the three turbines to receive equal amounts of air speed and generate the same amount of energy. The wind turbines are reported to have added $3.5 \%$ to the project cost, making for a relatively small payback period. Each turbine can start at a wind speed of $4 \mathrm{~m} / \mathrm{s}$ and a safety shut down speed of $25 \mathrm{~m} / \mathrm{s}$ and work at maximum efficiency at $12 \mathrm{~m} / \mathrm{s}$ which is the average wind speed of the site. (Stankovic, 2009) The turbines are supported by steel bridges which are attached to the building with motion absorbing bearings allowing each bridge to move $0.5 \mathrm{~m}$, absorbing any vibration caused by the rotating turbines without transferring any force to the towers. The most impressive part of the Bahrain WTC is the $120,000 \mathrm{~m}^{2}$ of office floor space built with environmentally responsible building services and façade for only $\$ 150$ million US (\$200 million NZ), this translates to $\$ 1667$ NZ per $\mathrm{m}^{2}$. (Bahrain World Trade Center, 2009) The new Telecom building in Wellington (image 5.8) which received 5 stars from GreenStar cost approximately $\$ 3846 \mathrm{NZ}$ per $\mathrm{m}^{2}$, more than double the Bahrain WTC. The Bahrain WTC needed to make some adjustments to the working turbines but have been fixed and is working as estimated. It has won several international 
awards and has changed the previous conception in the construction industry that full building integrated wind turbines where cost prohibitive. This project proved wind energy is economically feasible and wind energy can be displayed in a positive and public fashion. The key to the economic success of integrating the turbines into the project was using standard, off the shelf elements where ever possible and adjusting the building to suit.

The best example of wind turbine integration for a residential project is the Strata residential tower in London (image 5.9). At the top of $148 \mathrm{~m}$ tall tower are three building integrated $9 \mathrm{~m}$ turbines which will produce an estimated $50 \mathrm{MWh}$ per year which should be $10 \%$ of the buildings annual energy requirements. The building cost $£ 113.5$ million (\$240 million NZ) and has 408 apartments and a shopping complex on the ground floor. (DeFreitas, 2010) The energy efficient building will use recycled water and be connected to the new Elephant \& Castle MUSCo (Multi-Utility Services Company), "a community combined heating and power scheme. Independent analysis has compared CO2 emissions from Strata SE1 against the Building Regulations 2006 Part L2 targets. The result demonstrates that Strata SE1 will achieve a predicted 73.5\% reduction in $\mathrm{CO} 2$ emissions when compared against the Building Regulations benchmark." (DeFreitas, 2010) There was extensive wind assessment testing to select the shape of the shroud which would house the turbines to ensure maximum air flow through the swept area of the blades. The test used the original concept with $9 \mathrm{~m}$ square tapered shrouds, than with a $1 \mathrm{~m}$ filleted edge at the front and a rounded edge at the rear and the third with a $2 \mathrm{~m}$ filleted front edge and an altered canopy (image 5.10). The third case proved the most effective using a range of incoming incidental wind angles with a 35\% increase of mass flow through the turbines. In relative scale to the building, this project used smaller turbines than the other examples and therefore had to make sure that the turbine placement was configured for the maximum allowable energy yield. (Stankovic, 2009)

Image 5.8



(Maximus, 2008) 
Image 5.9
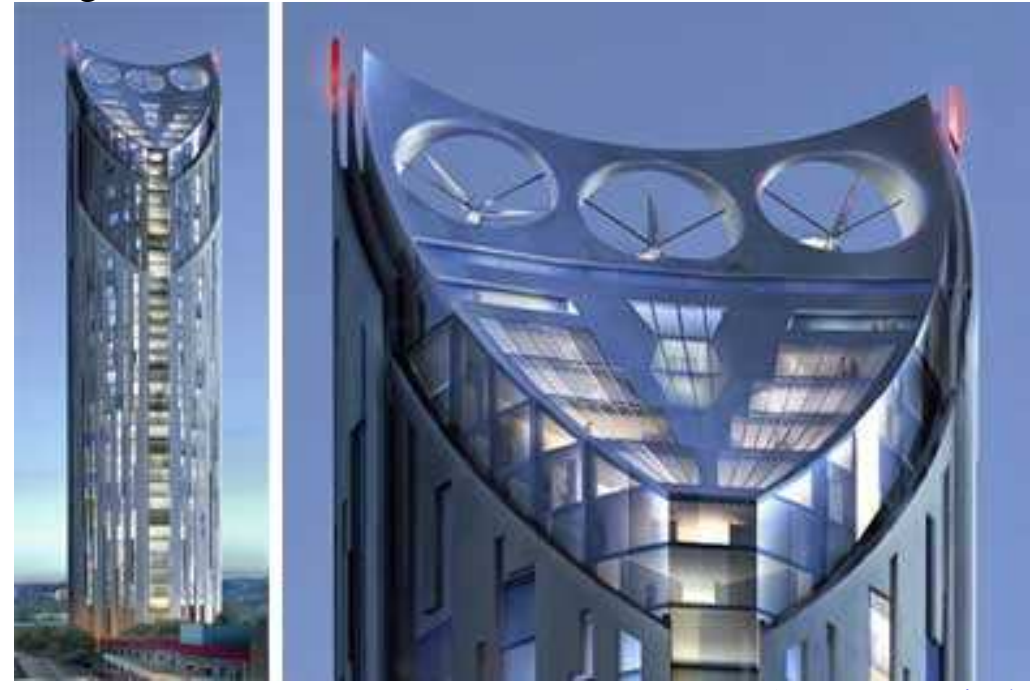

Image 5.10

(www.mywindpowersystems, 2009)


(Stankovic, 2009)

\section{$\underline{5.5-\text { Summary }}$}

The technological advancement involved in integrating turbines into building and energy grids is essential for the future of this new practice. BIWT technology is still at a point where if the advancement is not supported by governments and large scale corporations that have an obligation to the environment, it might be written off as a fad and forgotten. One of the main reasons why there are not more current built examples of integrated turbines is high costs. A main reason for high costs is there is not a large enough demand for mass produced turbines, causing expensive specifically designed products. The advancement of technology and social acceptance are the two factors which will determine the future for urban energy production.

From the cases studied it appears that the key to a successful project is using as much existing technology as possible and maximizing wind flow through the design of the shape of the area directly surrounding the turbines. Currently there is only a small amount of turbine options produced with enough quantity to allow economic feasibility and the key to product development is public social demand. 
Chapter 6

Wellington Wind Integration 


\section{1- Aim of Project}

To propose a wind powered energy project in Wellington, seems intrinsically straight forward. The benefits of wind power overwhelm any possible negatives, it is almost completely free of any carbon emissions and there is an unlimited free supply which can now be reasonably predictable. Wind power is the fastest growing environmentally friendly energy resource and is becoming increasing efficient with mass manufacturing and technological advances. The aim of my project is to design a building to serve as the national centre for urban wind power advancement, an iconic building which represents New Zealand's devotion to the future of clean energy production.

My aim is a building which has the ability to sustain its own energy consumption by incorporating wind turbines to produce the equivalent amount of energy it requires. The building will be designed to require the least amount of energy possible through both active and passive energy saving design. The combination will produce a healthy building with ideal working and living conditions. Producing a building which can display the benefits of urban wind power in a public, high traffic area could initiate further wind based projects. Ultimately a city with enough selfsustaining buildings could potentially create its own clean, sustainable energy grid.

\section{$\underline{6.2 \text { - Project Pre-Design Considerations }}$}

Designing a building follows a certain path depending on the projects size, location and intended usage. The design path is scripted by several parties and governed by local government which must consider the proposed buildings integration into the local context. These are the considerations and resulting decisions I have made during the design process of the project.

Site:

I chose the waterfront site (image 06.01) through a selection process of wanting a highly public site with heavy pedestrian traffic and needing an urban site which had the maximum unobstructed exposure to the predominant north and south wind. The waterfront site is currently occupied by the Shell Corporation which is a global petroleum company, the change in occupant is symbolic of the intended global shift away from petroleum based fuels towards clean, sustainable environmentally responsible energy production. The site is surrounded by one of the major pedestrian traffic routes in Wellington with very minimal vehicle traffic allowed along the waterfront. Adjacent to the site is TSB arena and the public square which hosts a variety of public events during the year and is the major connection route from the central business district to the waterfront.

The site has optimal access to unobstructed wind due to its waterfront location and the lower overall building height of the surrounding buildings, these factors combine to allow for powerful direct wind above 5 or 6 stories. The waterfront area 
known as "outer T" provides protection from the wind coming off of the water along ground level, providing comfortable conditions for pedestrians.

There has also been a recent surge in environmentally friendly buildings completed in the general vicinity of the site along the waterfront, several of which have been awarded green star ratings (image 06.02). There are a few other commercial projects which are currently proposed to rejuvenate the waterfront area and encourage a connection between the waterfront and the business district of the city.

\section{Usage:}

The move to design mixed use buildings in an urban has several environmental and social benefits. The ground floor will provide public space with retail and restaurant space to promote as much public interaction as possible and also serve as the entrance to the commercial and residential floors above. The area is a popular spot for lunch time and after work socialisation, along with the internal public space there will be several public seating areas created to increase public usage.

The commercial space will comprise the lower floors of the building and will house office and research space for alternative energy companies. To encourage interaction between companies involved in alternative energy can create synergies and collaboration which is needed to progress New Zealand's current alternative energy practise. Interaction will be encouraged through creating public areas and common social areas available to the public. These should include break and lunch areas and semi-protected common outdoor space.

The residential portion of the building will occupy the majority of the top portion of the building with each floor providing four separate residences. Each residence is designed to maximise passive space ordering, placing the most heavily used areas on the exterior of the building for natural lighting and heating. Any active assistance needed to provide optimal living conditions will be installed using the most efficient technology available. Small scale work space should be included to allow people to work and live in the same building eliminating commuting time and energy. Social interaction will be encouraged through public social space and common building circulation.

Mixed use buildings are becoming increasing common and have many benefits by decreasing commuting distance, allow heat exchange created during the day by commercial use to residential space at night and promotes interaction between social classes.

\section{Height Restrictions:}

The proposed site is currently situated in Lambton Harbour Area which has height restrictions of 18.5 meters, the height of the current Shell Corporation building. The proposed project would need to go through a resource consent process and granted special permission. The area directly adjacent to the site across Customhouse Quay has height restrictions of 80 meters, which I will use to make sure the scale of the proposed building relates to the immediate surroundings. This will cause some shadow consequences to the area, I will try and minimise the effect by using a circular building floor plate which tapers with elevation. There will always be some adverse effects of a new building, these must be considered and weighed against the positive 
contributions of the new proposal. The largest scope for improving the public experience of the area will be the ground floor of the building and the immediate surrounding exterior area including the public business square.

\section{Building Shape:}

My research on previous case studies have shown that the form of the building must provide a funnelling effect to the area immediately surrounding the turbine to increase wind speed. To reduce the wind loading to the rest of the building a curved floor plate will be used to allow the wind to pass around the building horizontally. The circular floor plate will also minimise shadows cast on the surrounding area. Having a circular floor plate and curved façade also has the lowest exterior surface area to floor plate area ratio reducing the amount of energy lost during the winter and heat gained during the summer. There is usually an issue of allowing natural sunlight to reach the middle of a building with a conventional circular or rectangular floor plate which will need to be considered.

These are all important issues which must be considered and implemented in accordance to achieving the overall project aim. Without going through the entire resource consent process I will proceed with the presumption that the projects height plane breach would be deemed acceptable by the city council based on the overall merits and public contribution of the building.

\section{$\underline{6.3 \text { - Landscape Design and Surrounding Area Context }}$}

The landscaping around the building is intended to promote pedestrian traffic through the site and also provide public seating and social areas beside the main traffic routes (image 06.03). Stairs, seating and varied levels have been used to create boundaries and define areas as either circulation or public seating and social space. I have used wooden seating and planter boxes to bring in natural elements which come in physical contact with users. The ground integrated paving to the north of the building gradually introduces the user to the new area and blurs any boundary lines. I have installed a turbine to the garden area to introduce a visual tie at ground level to pedestrians but while turning it would also create air movement which could be felt at ground level, creating a public experience with wind power (image 06.04).

The proposed square to the north of the main building provides public exterior work space and inside provides safe bicycle parking (image 06.05). The exterior levels are work spaces which allow people to leave their office and use the space for private work or even scheduled meetings, promoting public interaction with the site. Each table will provide electrical outlets, with power supplied from the $15 \mathrm{~kW}$ horizontal axis triple helix turbine, as well as data and internet service allowing people to do a variety of work tasks. The floors are grass to provide a less formal and comfortable work space. There are three different types of configurations available; the first a standard table with benches each seating 6 to 12 people, the second a similar sized table located closer to the ground for people who wish to sit directly on the grass but still have a table to work on and the third are simple connection panels allowing people to sit or lay on the grass and still use their laptop. The circulation is cyclical, representative of the path of a turbine, which is a theme used throughout the 
project. The public space is comprised of two different level spaces allowing the users to feel the influence height has on increasing wind speed. The sails provide shelter and tie the area to the public square between the proposed building and TSB Arena. The horizontal axis turbine was chosen for the minimal sound emission and low wind start up speed.

\section{$\underline{6.4-\text { Building Entrance and Ground Floor }}$}

The building entrances are positioned in the cuts in the building to provide hierarchy and emphasize both the entrances and the cuts in the building (image 06.06). The fully glazed roof and stepped balconies to the first and second floors blend the transition from exterior to interior and blur the definition of the balcony space (image 06.07). The red vertical glazing structure accentuates the entrance and emphasises the vertical aspect of the red building cuts. Glazing is used throughout the ground floor to pull natural sunlight into the middle of the building and provide a visual connection to the interior of the building. The roof of the ground floor is broken up to pieces to emulate the image of a traditional rectangular building form which has been twisted and broken from the new buildings twisted form (image 06.08). This is also to break up the facades into smaller sections and reduce the visual scale of the building. The reduced scale of the ground floor elements, staggered floor plan and the pedestrian focused landscape design create an interesting human scaled environment which engages each passing pedestrian without overwhelming them.

\section{$\underline{6.5 \text { - Building Core and Central Stairwell }}$}

The central building core provides both the main structure and circulation for the entire building, similar to the tower and nacelle of a turbine (image 06.09). The ground floor area of the building core has been elevated to provide a central focus and place emphasis on the stairwell. The central stairwell serves several purposes and is the central focus on the entire building, encouraging use and physical activity. Its main purpose is to obviously provide vertical movement through the building. The circular rotating shape of the stairs mimics the movement of the turbines, creating a similar movement of the building users. Secondly the stairwell acts as a stack ventilation chimney providing passive ventilation. The stairwell also allows sunlight from above and provides a visual link from all floors to the working turbines. Finally the stairwell acts a sculpture publicising people who choose to use the stairwell rather than the elevators.

The building core on the commercial floors is designed to encourage social interaction between companies which occupy the same floor (image 06.10). I placed the kitchenette and the seating for breaks in a common area to promote informal communication.

The building core on the residential floors is used for small 1 to 3 people business spaces allowing people the opportunity to work from within the building (image 06.11). 


\section{$\underline{6.6-\text { Structure }}$}

As mentioned, the building structure is all based around the circular re-enforced concrete core which provides the gravity loading, shear loading and torsional rigidity. The building structure while unconventional provides the buildings identity and is based on a simple theory of stacked circles and perfect balance. The theory is similar to the structure used for 30 St. Mary Axe (image 06.12). The St. Mary building was designed by Foster and Partners and sits high in the London skyline at 180 metres, it uses a steel core and has six triangular fingers cut out of the circular floor plate. Each floor rotates five degrees to create atrium space which spirals up the building. This allows natural sunlight deeper into the floor plate and provides natural ventilation. This is the same structural strategy I have used, although I decided to use a re-enforced concrete as the main structure for its thermal retention properties. Each floor is perfectly balanced around the central core allowing centre of mass to carry the gravity load, which is in the centre of each floor plate and in the middle of the $600 \mathrm{~mm}$ thick concrete ring which has and outer diameter of $24 \mathrm{~m}$. The structural ring column also works a shear wall and because of the mirrored floor plate the centre of mass is also the centre of rotation causing an eccentricity of zero. The large eye shaped openings allow sunlight into the central space and due to their elliptical shape running parallel to the gravity loads the concrete is never subjected to any tensional loading.

The floor plates are reinforced concrete with a $100 \mathrm{~mm}$ toping and a $300 \mathrm{~mm}$ waffle grid substructure to distribute any point loads evenly across the floor plate. The waffle grid allows for the large amount of reinforcing needed to transfer any tension loading to columns while reducing the weight of the floor significantly.

Due to the project being on reclaimed land there would be some deep piling needed, although the circular shape of the building would reduce the wind loading substantially. The wind force which usually travels vertically along a rectangular or square building, now travels around the building producing positive pressures on the windward area and negative pressure to the rest of the façade. This effect is also very useful when used to produce cross flow natural ventilation.

In certain low load areas the concrete used can filled with up to $65 \%$ industrial waste such as fly ash, a by product of smelting process which significantly cuts down on carbon dioxide emissions during processing. All steel reinforcing used must be marine grade due to the proximity to the salt water.

\section{$\underline{6.7-\text { Exterior Facade System }}$}

The exterior facade of a building regulates the buildings temperature and therefore determines how much energy it consumes. Glazing allows natural sunlight into a building but has traditionally released most of the heat. Years of research has resulted in double or triple glazed sealed spandrel panels trying to gain the lowest 
U- value possible. The glazing suite I have chosen is the Thermotech triple glazed argon filled low-e panels with silicone foam spacers, which combine for a $U$ value of $0.71 \mathrm{~W} / \mathrm{m}^{2} \mathrm{~K}$. The lower dark portion of the panel is filled with an organic paraffin phase change material which works as a latent heat storage system. The double layered glazing is separated by a one metre cavity which acts as a temperature buffer and allows the building to passively ventilate itself, which I will discuss in the next chapter in more detail. The interior glazing runs from floor to ceiling on each level and is combined with the automated blinds which sit in the cavity next to the internal glazing. The internal glazing layer also houses the air intake for the localized heat exchanger ceiling unit which provides any additional heat required. The exterior glazing is supported by the square truss ties which twist along the corners of the building cuts and are tied to the floor plates.

\section{$\underline{6.8-\text { Services }}$}

The building has been designed to passively self-regulate temperature and ventilation while still being almost completely glazed to maximize the city and harbour views. The double skinned cavity façade is the key to both temperature regulation and passive ventilation. The building functions as building inside a building using the cavity to move and expel unwanted hot air, allow fresh clean air to enter and circulate through the building and works as a transition space to buffer the temperature difference between inside and outside.

During the summer the sun heats up the air inside the cavity which rises due to the stack effect and is then sucked outside by vents near the top of the building by the suction created from the wind passing by the circular building (image 06.13). The vacuum inside the cavity pulls air in from ground level which has been cooled by passing over the water and is distributed to each floor by openings in the internal glazing layer. The blinds allow the sunlight to penetrate the exterior glazing layer but get trapped in the cavity and expelled out the top without entering into interior of the building. Any interior hot air is pulled up the central stairwell and vented out the top, this movement allows for passive fresh air exchange.

In winter the cavity acts as a large layer of insulation which allows the heat that is gained during the day from the sun and stored in the concrete to remain inside (image 06.14). The commercial portion of the building produces heat during the day from people and equipment which rises to heat the residential portion of the building which requires the heat at night when the businesses are closed. Any additional heating required would come from in centralised heat exchange unit and controlled by temperature sensors in each unit. The heat exchange unit receives hot water from the 40 solar water heating panels located on the roof and are topped up by an electric hot water heaters if needed (image 06.15).

All of the services in the building are controlled by a building management system which has a range of internal and external sensors. The system monitors temperature, moisture, lux levels, occupancy and carbon dioxide to co-ordinate all systems to work together and to maintain optimal building conditions, while not wasting any energy. The building management system is connected to the window 
openings, blinds, ventilation system, artificial lighting and the heating system. All of the controls can also be controlled by the local building user if desired.

The roof holds 40 solar hot water heaters and a rain water collection system which stores water in the services area for toilet flushing. Low flush toilets and low flow taps have been used throughout the building.

\section{$\underline{6.9-\text { Summary }}$}

Designing a building to use as passive energy exchange combined with smart sensors and controls is the most important factor in maximising energy efficiency. Buildings should use natural wind and sun energy to regulate its conditions, rather than simply blocking them out as much as possible. Controlling weather intake and local site specific environmental conditions must be the primary design factor in creating an efficient building. The next step is estimating the amount of generated energy your building will require to function properly and deciding if it is economically or environmentally feasible for the building to produce its own energy. For my proposed site the local weather research have shown that wind power is the dominant potential source of energy. In the next chapter I will discuss how I have integrated wind turbines and the resultant design and energy production. 
Chapter 7

Project Results 


\section{1- Technology Used}

The turbine configuration for the top of the building consists of five total turbines: three triple bladed traditional horizontal axis turbine and two triple helical horizontal axis turbines. The turbines are set in series and geared to work at each turbine's maximum efficiency. The traditional turbines are much more productive at higher speeds, while the triple helical turbines are suited towards lower or unidirectional wind speeds. In either high or low wind speed conditions two of the five turbines would perform at its highest output. The $21 \mathrm{~m}$ diameter Dezhou Aerosa WT-210 traditional triple blade turbine has a start up speed of $8 \mathrm{~m} / \mathrm{s}$ and a maximum cut out speed of $80 \mathrm{~m} / \mathrm{s}$. The triple helix turbines can produce $45,300 \mathrm{kWh}$ annually and have a start up of $3 \mathrm{~m} / \mathrm{s}$ and cut out at $50 \mathrm{~m} / \mathrm{s}$. The combination of the different turbines allow the entire system to always work at the most efficient state possible depending on wind speed and direction.

\section{2- Local Weather Parameters}

With an annual average wind speed of $22 \mathrm{~km} / \mathrm{h}$ Wellington has an abundance of wind power. This number represents the conditions at ground level in a relatively open setting. To get a more accurate calculation of wind conditions where our turbines will be placed we need to take into account turbine height and the city topography. The first step is to calculate the wind speed at the height of the turbines, the speed increase at a 1/7 power, which takes into account an urban site next to a large body of water. The formula is $\mathrm{U} / \mathrm{Ur}=(\mathrm{Z} / \mathrm{Zr})^{\wedge} 1 / 7$, where $\mathrm{U}$ is wind speed and $\mathrm{Z}$ is height and $\mathrm{Ur}$ and $\mathrm{Zr}$ are the proposed wind speed and height. The annual average wind speed of $22 \mathrm{~m} / \mathrm{s}$ is taken from a weather data collector which sits at a height of $3 \mathrm{~m}$; our turbines will sit at a height of $71 \mathrm{~m}$. At this height the annual average wind speed will therefore be $34.5 \mathrm{~km} / \mathrm{h}$ or $9.6 \mathrm{~m} / \mathrm{s}$. This annual average speed is ideal for wind power production.

\section{3- Predicted Energy Requirements}

Now that we have determined that the site is suitable for a wind turbine, we must estimate how much energy our proposed building will require. We can estimate what energy the building will need to consume to maintain a comfortable temperature depending on area usage, healthy air quality and proper lighting levels. We can also estimate what percentage can be saved from efficient technology and passive design but energy conservation also has a dramatic human component which can only be encouraged but not necessarily predicted.

The commercial portion of the building has a considerably higher energy use per square metre than the residential, which is due to the equipment and lighting needed. It is generally regarded that a typical commercial business will use $350 \mathrm{~kW} / \mathrm{h}$ per year per square metre. The energy usage is usually divided evenly amongst; HVAC, lighting and equipment. As a reference I will use the Geyser building in 
Parnell, Auckland which has a similar environmentally focused design strategy and vented double skinned fully glazed external façade. It is built in an area with similar weather conditions and represents a conceivable level of design within New Zealand, using best practice environmental goals. I will use a conservative commercial energy consumption of $110 \mathrm{~kW} / \mathrm{h}$ per square metre per year, although the Geyser predicts it's usage at $95 \mathrm{~kW} / \mathrm{h}$. My proposal has a total commercial floor area of $12,400 \mathrm{~m}^{2}$, which gives an annual energy requirement of $1,364,000 \mathrm{~kW} / \mathrm{h}$.

The residential portion of the building occupies 13 floors and consists of 45 separate residences from $250 \mathrm{~m}^{2}$ to $330 \mathrm{~m}^{2}$ (image $07.01+07.02$ ). The average New Zealand stand alone household with the same floor area uses $7630 \mathrm{~kW} / \mathrm{h}$ per year. Using solar hot water heating, sensored lighting and passive temperature control an average apartment should use $2500-3000 \mathrm{~kW} / \mathrm{h}$ per year. We will use $3000 \mathrm{~kW} / \mathrm{h}$ per residence for an overall residential energy demand of 135,000 kW/h per year. Both commercial and residential estimates have used the higher end of the estimated usage to be safe but would more than likely be quite a bit less than stated.

The top floors of the building are plant rooms and should contribute an extra energy demand of $51,000 \mathrm{~kW} / \mathrm{h}$ for a total building requirement of 1,550,000 kW/h per year. At the approximate current rate of electricity in Wellington of $\$ 0.20$ per $\mathrm{kW} / \mathrm{h}$ it totals an annual electricity bill of $\$ 310,000$. A building of similar size and usage designed using cost as the main design driver would have an estimated annual energy cost of one million dollars.

\section{4- Predicted Energy Produced}

The project WEB study showed that one of main strategies to keep cost down in a building integrated wind turbine project was to use already available products as much as possible. For the 3 bladed traditional turbines I have used the NorthWind 100 Wind Turbine by Distributed Energy Systems. It is a synchronous, variable speed, permanent magnet, direct drive generator and was designed to be low cost and low maintenance. (Systems) With an annual average wind speed of $9.6 \mathrm{~m} / \mathrm{s}$ the NorthWind 100 has an output of $475 \mathrm{MWh}$ or $475,000 \mathrm{kWh}$. This would be the output for one installed turbine in a stand alone installation. The proposed design would allow the first exterior turbine to produce this quantity of energy, the turbine sheathing and exposure to the first turbine will alter conditions for the subsequent turbines. The entrance of the sheathing is $28.5 \mathrm{~m}$ in diameter, the outer turbine has a diameter of $21 \mathrm{~m}$ leaving an uninterrupted area of $292 \mathrm{~m}^{2}$. This uninterrupted area would combine with the wind power left over from the wind swept area of the first wind turbine, which is $1 / 3$ of the overall wind power. The wind speed hitting the first turbine is $9.6 \mathrm{~m} / \mathrm{s}$ annually, $1 / 3$ of that is $3.2 \mathrm{~m} / \mathrm{s}$ over a wind swept area of $380 \mathrm{~m}^{2}$. The formula for Watts produced from a turbine is $\mathrm{W}=\mathrm{Cp}$ (air density)(wind swept area)(wind velocity ${ }^{3}$. The sheathing will increase average wind speed by $2.5 \mathrm{~m} / \mathrm{s}$ as shown by project WEB. For the uninterrupted area at the entrance of the sheathing the equation is $\mathrm{W}=(.35)(.5)(1.29)(292)\left(12.1^{3}\right)=116,780 \mathrm{~W}$. The equation for the wind power left after the first turbine will be $\mathrm{W}=(.35)(.5)(1.29)(380)\left(5.7^{3}\right)=15,887 \mathrm{~W}$ or $75 \mathrm{MWh}$ for a total of $132,667 \mathrm{~W}$ which would produce $627,000 \mathrm{kWh}$. The third 
turbine in series would receive $44,222 \mathrm{~W}$ and would produce $188,000 \mathrm{kWh}$. The overall estimated energy production would be a sum of 1,290,000 KWh (image 07.03). The overall building energy requirement at 1,550,000 $\mathrm{kWh}$ subtracted the produced energy $1,290,000 \mathrm{kWh}$ leaves a need for $260,000 \mathrm{kWh}$ or $260 \mathrm{MWh}$. There are several factors which can affect the amount of energy produced and consumed throughout a building so it is still difficult to be completely accurate if a building can be self sufficient.

\section{$\underline{\text { 7.5- Overall Economic Results }}$}

One of the main factors in estimating building integrated turbine feasibility is economic efficiency and pay back period. With current electricity prices the proposed turbine installation would save $\$ 258,000$ a year. The generated electricity along with the energy saving from an environmentally responsible design and products would combine to save just under a million dollars annually. An acceptable pay back period for energy efficiency based technology, depending on client, is in the 10-20 year range. If the client would accept a 15 year pay back period the additional cost of integrating the turbines would therefore need to be under $\$ 3.8$ million dollars. The Bahrain World Trade Centre stated that the additional cost for their turbines was an additional $3.5 \%$, which was deemed completely acceptable. If our turbines were to use the same percentage the overall project would need an overall project budget of $\$ 108$ million dollars. This is slightly below the $\$ 120$ million dollar cost of One Featherston St. which is almost complete in Wellington, and built for a cost of $\$ 2500$ per square metre of office space. The proposed project is $39,500 \mathrm{~m}^{2}$, this would allow for a budget of $\$ 2735$ per $\mathrm{m}^{2}$. In planning projects of this size a preliminary estimate and design strategy is put in place to begin the project, this evolves over the design period and project elements are revised to suit budget and overall project goal. From the initial design and research I have done for the proposal it appears that it is completely feasible and could perform as well or better than some current built examples.

\section{6- Summary}

Predicting costs and building performance with projects that have so few similar predecessors it is often quite difficult to get an accurate as estimate as other standardized projects. Due to this, estimations and calculations must be based on theory and as much site testing prior to construction as possible. These calculations and predictions have shown that Wellington city is the ideal location for urban wind integration. With these conditions comes a responsibility to further the possibilities of building integrated energy generation and promote Wellington as an environmentally conscientious city.

Economic performance is important for all new projects and is paramount for a project to serve as an icon of environmental performance, energy saved directly relates to money saved. The challenge comes from helping clients to realise that 
performance rather than price as a project driver will create the most success and efficiency over the life of the building. 
Chapter 8

Conclusion 


\section{1- Environmental Contributions}

Changing the way we design buildings must be initiated by countries that have the resources to do so. In the past New Zealand has experienced a significant delay in implementing energy efficient design standards and receiving environmentally focused technology. With the current shift towards environmental focused architecture also comes the ability to change this. New Zealand advertises itself to the rest of the world as 'clean and green', yet the building industry is anything but. The powerful wind and sun in Wellington combined with rough terrain and a relatively mild temperature produces the ideal location to test and utilise a range of alternative energy production. Urban integrated wind energy production has been introduced to the world and shown it is a feasible option and the case studies suggest that New Zealand needs to increase in wind power portfolio to reduce it heavy dependence on hydro power. I have shown that Wellington has all the conditions necessary for a feasible building integrated wind turbine project, the only item remaining is a client or government with enough environmental dedication to implement the technology.

Turbines built on their own have a positive environmental contribution, but if they are occupying previously natural areas and providing energy to buildings which waste electricity due materials that perform poorly that contribution is nullified. Clean energy should be provided to buildings which maximise efficiency, building integrated wind turbines are the perfect combination and solution.

\section{$\underline{\text { 8.2- Urban Contributions }}$}

The integration of wind turbines faces several issues in the urban context which must be dealt with completely and in the early stages of design. Negative public opinion can occur if a turbine is overtly loud or is deemed a threat to public safety, these are technical issues which can be overcome with proper design. I have placed the turbines in a large sheath which acts as a wind accelerator, but also provides acoustic dampening and a visual barrier between the turbines and city to block any flickering reflections. The top floors of the building which surround the turbines are plant rooms and act as an acoustic barrier for the rest of the building.

The main urban issues that are site specific to the project is the breach of allowable building height and the shadows cast on the surrounding area. A special exception would need to be made during the resource consent period but a building which has the ability to act as an icon should prove an acceptable exception. The circular shape of the building has a significant reduction in the shadow cast and the majority of the area affected by the shadow of the building is either other buildings, water or road, but this is one aspect of any larger scale project that is unavoidable.

Although the shape of the proposed project is quite different than the surrounding buildings, the buildings general size matches the scale of the adjacent buildings (image $08.01+08.02+08.03$ ). I have replicated the scale of the surrounding area through the size of the glazing panels and expressing the floor to floor height on the exterior of the building. Pedestrian scale was dealt with by the 
ground floor articulation and staggering the façade elements to break up the overall size of the building experienced by passing pedestrians.

Presenting a foreign object into the urban fabric presents several obstructions but in order to change the focus of an industry you need an icon to express the idea in a dramatic fashion.

\section{$\underline{\text { 8.3- Economic Contributions }}$}

Energy saved or produced is equated to money saved, making it hard to decipher if environmental based projects are about saving money or the saving the earth. Regardless of motive, the economic feasibility of energy producing projects is usually the most important issue, specifically energy produced compared to integrating the additional technology. Some government projects or overtly wealthy clients have to ability to accept longer payback periods or allow the overall positive contribution to trump any additional costs; projects with these allowances are too scarce to allow any main steam integration. In order for building integrated wind turbines to become a realistic option it must have a payback period of 15 years or less.

My research has shown what has been previously acceptable turbine integration rates for completed projects and the possible budgets for local large scale projects; the energy production and economic calculations all show that a turbine integrated building is completely feasible in Wellington.

\section{4- Consequential Questions}

The next step in the proposed project would be to apply for resource consent and obtain an estimate from a Quantity Surveyor. The proposal would than need to be adapted to meet budget and receive consent. This would require some time and resource as projects with such abstracted forms often are the subject of controversy and can meet opposition from council. What exceptions from local urban regulations should be allowed for projects which have the ability to transcend local context and have global impact?

If projects have the ability to reduce waste, carbon dioxide and energy usage why hasn't it been made compulsory in a country which exists and thrives on a natural healthy landscape? With the ability to produce clean energy the task of implementing the responsibility lies with the government.

Energy conservation is the first shift in construction for a society focused on consumption and accumulation. Clean energy production along with the protection of natural resources is the next consequential step. The final step will be to re-evaluate what we have been taught is acceptable levels of consumption. Not only consumption of energy and natural resources but consumption of space which like petroleum is a fixed quantity and with the current rate of consumption will be exhausted. 


\section{$\underline{8.5-\text { Summary }}$}

Through the process of the project I stated the project aim of replacing global non-renewable energy consumption with the proposed solution of integrating electricity producing turbines into our urban environments. I than described the origins of wind power and the current energy conditions in New Zealand. The third chapter discussed the different aspects of proposing a building integrated wind turbine, which was followed by the local building conditions and industry in Wellington. I than described the recent and available turbine technology. Chapter 6 described the different building elements of the proposed project and how they function. This was followed by the data and results of the project describing the successful conditions and performance of the proposed project. The last chapter showed the viability and contributions of a proposed turbine integrated project in Wellington fulfilling the initial project aim.

Locally Wellington has the ability to generate a substantial amount of wind powered energy which is completely renewable and economically feasible. Urban based wind turbines not only have the ability to produce clean energy, but will also create public attention increasing the general public's interest and opinion of wind power. Without a shift in resource consumption and a push towards using renewable energy resources, current consumption trends will continue depleting natural resources and accelerating the degradation of the Earth's natural environment. 
Bibliography

30 St Mary Axe. "30 St Mary Axe". London, 2008. <http://www.30stmaryaxe.com/>.

Andy Keys, Andrew Baldwin, Simon Austin. "Designing to Encourage Waste Minimisation in the Construction Industry." Department of Civil and Building Engineering (2010).

Auer, Thomas. Performance as a Goal Integration as the Approach. The Future Envelope 1 a Multidisciplinary Approach. Ed. Ulrich Knaack and Tillmann Klein. Amsterdam: IOS Press BV, 2008.

Bahrain World Trade Center. "Bahrain World Trade Center, a New Era". Bahrain, 2009. <http://www.bahrainwtc.com/>.

Bussel, G J W Van. "An Assessment of the Performance of Diffuser Augmented Wind Turbines." ASME Joint Fluids Engineering Conference 3 (1999).

Clements-Croome, Derek. Intelligent Buildings. London: Thomas Telford Publishing, 2004.

Corbusier, Le. Towards a New Architecture. New York: Praeger, 1970.

DeFreitas, Susan. "London's New Strata Skyscraper Incorporates Wind Turbines". London, 2010. 〈www.earthtechling.com>.

Department of Conservation. "New Eco-Friendly Doc Building Opens". Wellington, 2007. Media Releases. Department of Conservation.

$<$ http://www.doc.govt.nz/about-doc/news/media-releases/2007/new-ecofriendly-doc-building-opens/>.

Energy Information and Modelling Group of the Ministry of Economic Development. "New Zealand Energy Data File." (2010).

EWEA. "European Best Practice Guidelines for Wind Energy Development,." EWEA (2000).

Fisher, Dr. David. "Dynamic Tower Overview". 2010. $<$ http://www.dynamicarchitecture.net/home.html $>$.

Goran Strbac, Danny Pudjianto, Anser Shakoor, Manuel Castro, Guy Waipara, Grant Telfar. "Summary of Findings New Zealand Wind Integration Study." (2008).

Green Star. "About Green Star Nz". Auckland, 2008. New Zealand Green Bulding Council.

Industry, Energy Technology Support Unit for Department of Trade and. The Assessment and Rating of Noise from Wind Farms, 2008.

International Energy Agency. "Energy Policies of Iea Countries." (2006).

---. "Renewables and Waste in New Zealand 2007". 2007. 2010. $<$ http://www.iea.org/stats/renewdata.asp?COUNTRY_CODE=NZ>.

Key Energy Ltd. "Feed-in Tariffs for Uptake of Renewable Energy." (2007).

Klein, Ulrich Knaack and Tillmann. The Future Envelope 1 a Multidisciplinary Approach. Research in Architectural Engineering Series, Volume 8. Amsterdam: IOS Press, 2008.

Maximus. "Jolly Green Giants". 2008. Ed. Eye of the Fish. $<$ http://eyeofthefish.org/jolly-green-giants/>.

McDougall, Stephan. Interviews. Wellington, 2009.

McKeough, Tim. "A Prefab, Rotating Skyscraper Coming to a City New You?" Architectural Record 196.8 (2008): 38.

Medici, D. "Experimental Studies of Wind Turbine Wakes - Power Optimisation and Meandering." Royal Institute of Technology (2005). 
Ministry of Economic Development. "Powering Our Future - Towards a Sustainable Low Emissions Energy System." Ministry of Economic Development (2006).

New Zealand Green Building Council. "New Zealand's First World Leadership Green Building". Wellington, 2009. Building Best Practice.

<http://www.nzgbc.org.nz/main/resources/articles/GeyserFirst6GreenStarBuil ding $>$.

New Zealand Wind Energy Association. "Climate Change and Wind Energy". wellington, 2010. 〈http://windenergy.org.nz/wind-energy/climate-change>.

---. "Electricity Prices". Wellington, 2010. <http://windenergy.org.nz/windenergy/electricity-prices>.

New Zealand Wind Energy Association, and "Nz Wind Farms". Wellington, 2010. <http://windenergy.org.nz/nz-wind-farms/nz-wind-farms $>$.

Post, Dominion. "Wellington So Windy?". Dominion Post April 12. 2010, sec. A7.

Pritzker Jury. "Jury Citation". 2008. The pritzker architecture prize. <http://www.pritzkerprize.com/laureates/2008/jury.html>.

Project WEB Partners. "Wind Energy for the Built Environment (Project Web)

" European Wind Energy Conference \& Exhibition (2001).

Quiet Revolution. "Qr5". London, 2010. <http://www.quietrevolution.com/qr5turbine.htm>.

Randl, Chad. Revolving Architecture a History of Buildings That Rotate, Swivel and Pivot. New York: Princeton Architectural Press, 2008.

Reuk. "What Is a Darrieus Wind Turbine". London, 2010. Ed. Reuk. <http://www.reuk.co.uk/Darrieus-Wind-Turbines.htm>.

Sanderse, B. "Aerodynamics of Wind Turbine Wakes." Energy Research Centre of the Netherlands.

shape NZ. "New Zealanders' Choice of Future Energy Sources." April 7, 2008 ed: shape NZ, 2008.

Sinisa Stankovic, Neil Campbell, Alan Harries. Urban Wind Energy. London: Earthscan, 2009.

Smedman, M Magnusson and A S. "Air Flow Behind Wind Turbines." Journal of Wind Engineering and Industrial Aerodynamics 80 (1999).

Society of Oxford Engineers. "The Basic Flow Mechanics of a Darrieus Turbine". 2008. Ed. Society of Oxford Engineers.

<http://www.soue.org.uk/souenews/issue7/tidalturbines.html $>$.

Stokhuyzen, Frederick. The Dutch Windmill. New York: Universe Books inc., 1963.

Strahan, David. "From Ac to Dc: Going Green with Supergrids." New Scientist.2699 (2009).

sustainable synergy. 2010. <www.masdarcity.ae/en/index.aspx $>$.

Systems, Distributed Energy. "Northwind 100 Wind Turbine." Wallingford 2007.

Tahbaz, Mansoureh. "The Estimation of the Wind Speed in Urban Areas." Shahid Beheshti University (2006).

Taub, Steven. "The $50 \mathrm{Gw}$ Renewable Scenario " Power Engineering.November (2003).

Te Ara. "Windy Wellington". Wellington, 2010. <http://www.teara.govt.nz/en/wellington-region/3>.

The Oil Depletion Analysis Centre. "Peak Oil Prime". London, 2009. < http://odacinfo.org/peak-oil-primer>.

Thermotech. "Fiberglass Windows-Thermal Performance."

Timmers, G. "Wind Energy Comes to Town." Renewable Energy World 4.3 (2001).

Tong, Fung. "Predicting the Post-Limit Softening Response of 


\section{Structural Materials by Implementing}

Finite Element Analysis." Atkins Technical Journal 3 (2010).

UK Energy Research Centre. "Global Oil Depletion - an Assessment of the Evidence for a near-Term Peak in Global Oil Production." (2009).

Watts, Andrew. Facades Technical Review. London: RIBA Publishing, 2007.

Wong, Linda Groat and David. Architectural Research Methods. New York: John Wiley \& Sons, 2002.

World, Renewable Energy. "Are Decibel Levels the Most Important Metric for Determining Impact?" Measuring Wind Turbine Noise (2010).

World Wind Energy Association. "World Wind Energy Report 2009." (2010): 4-7.

www.mywindpowersystem.com. "Strata Tower London- Elephant \& Castle". 2009. $<$ http://www.mywindpowersystem.com/windgallery/2009/11/strata-towerlondon-elephant-castle/>.

Yin, Robert K. Case Study Research Designs and Methods. 4 ed. Los Angleas: Sage, 2009. 


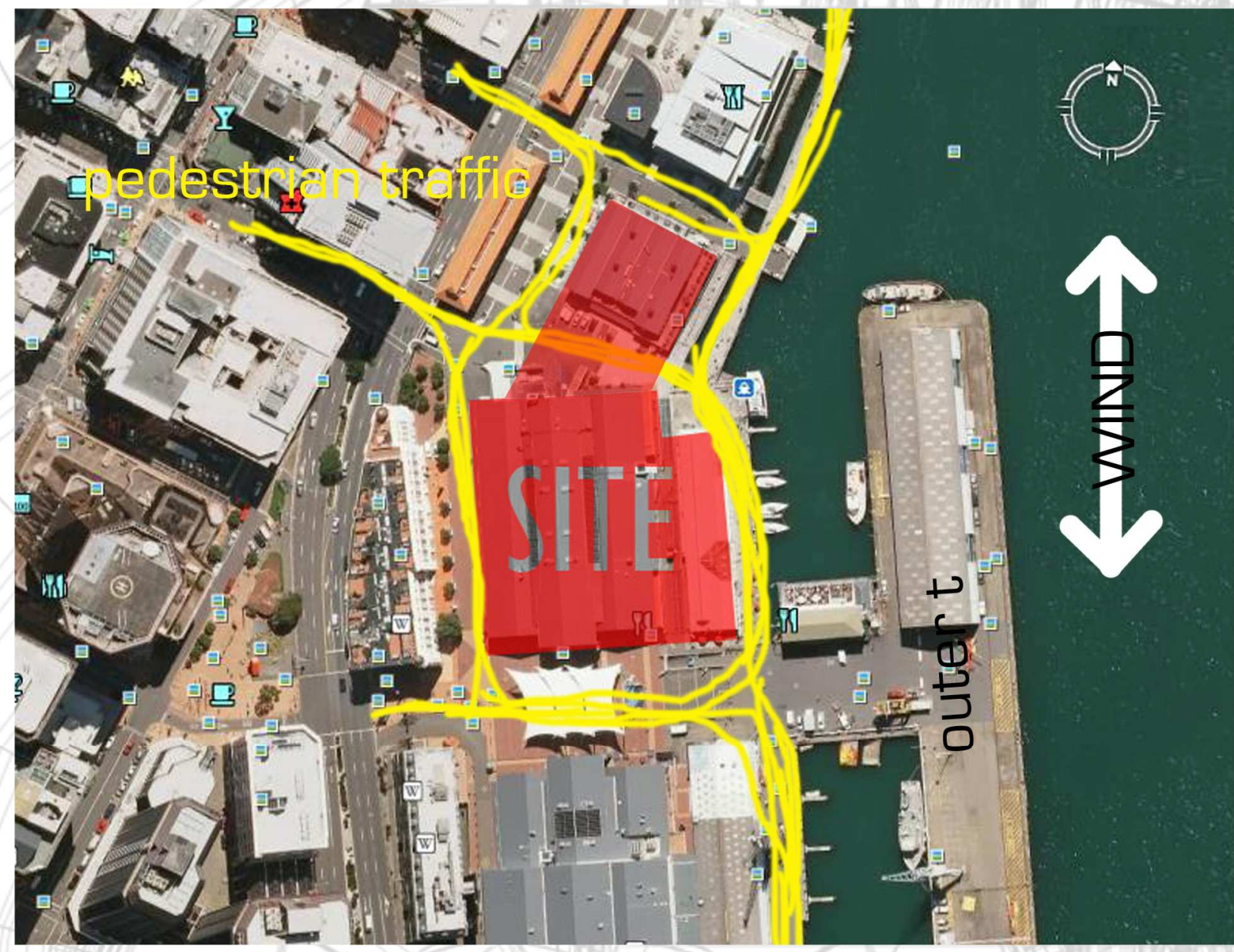

06.01

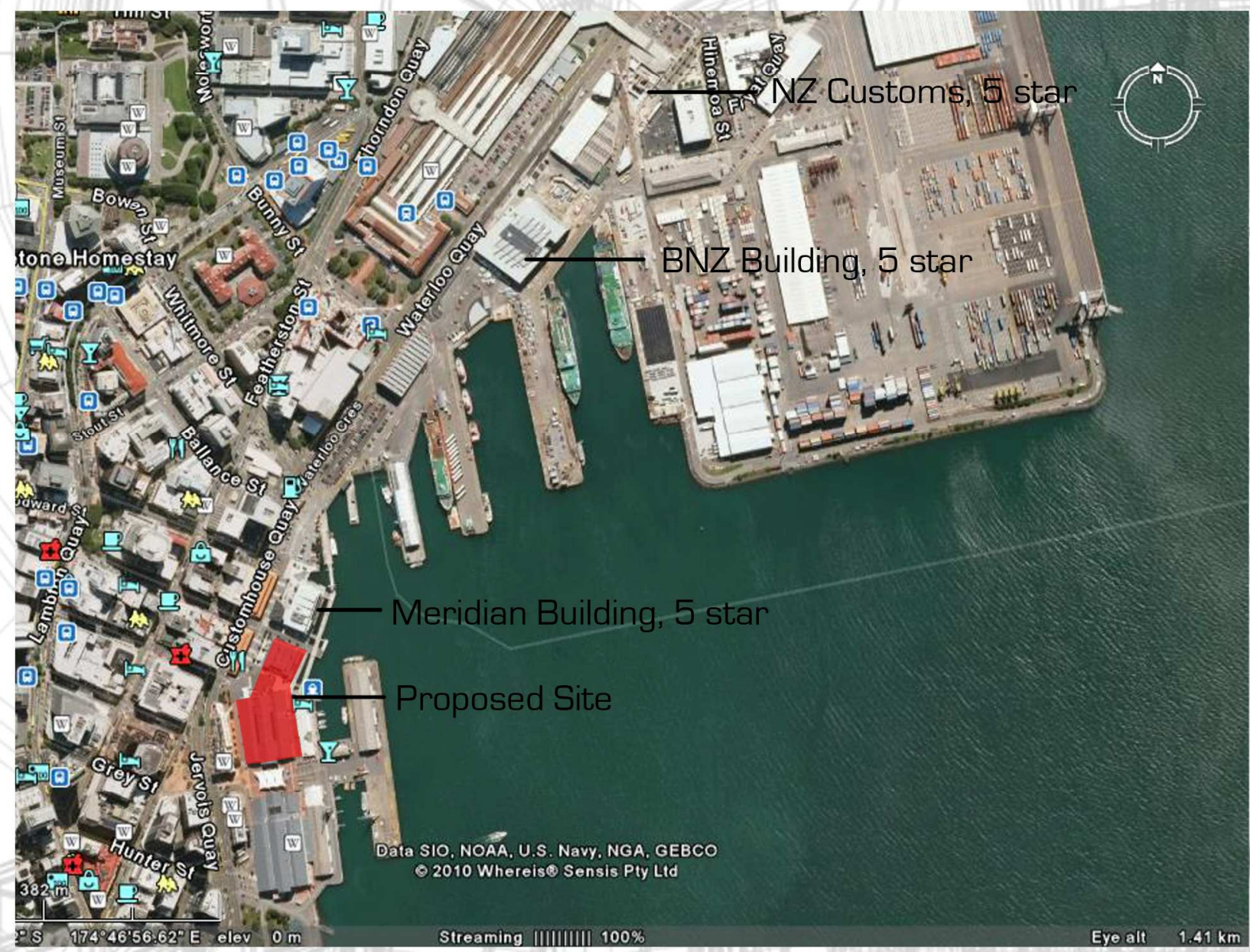

06.02

the alternative energy building collin crabbe 


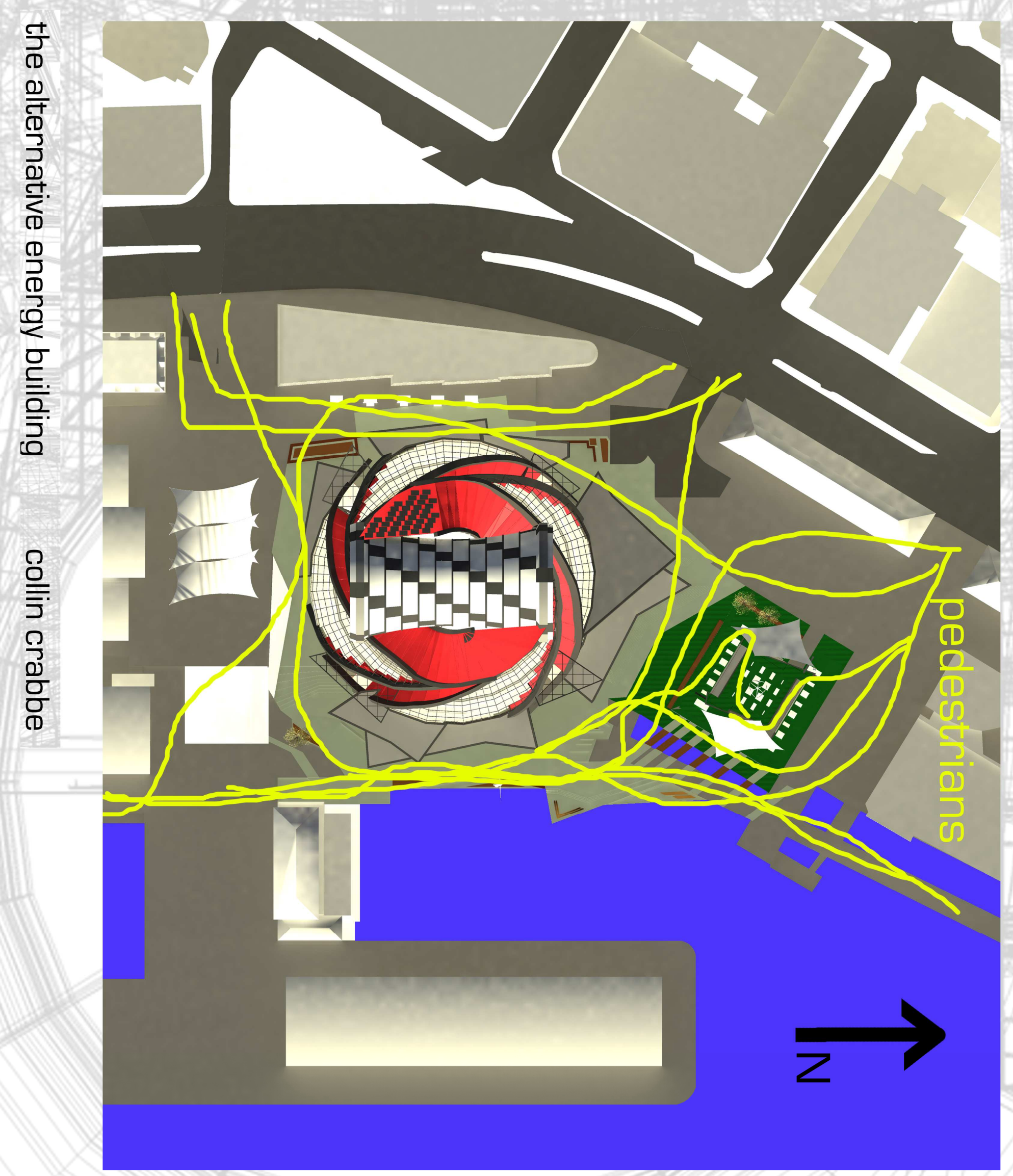

品 


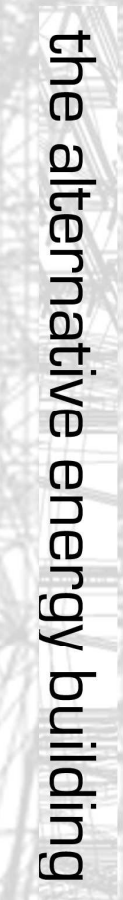

8
$\frac{0}{\bar{J}}$
$\frac{0}{0}$
$\frac{0}{0}$
$\frac{0}{0}$

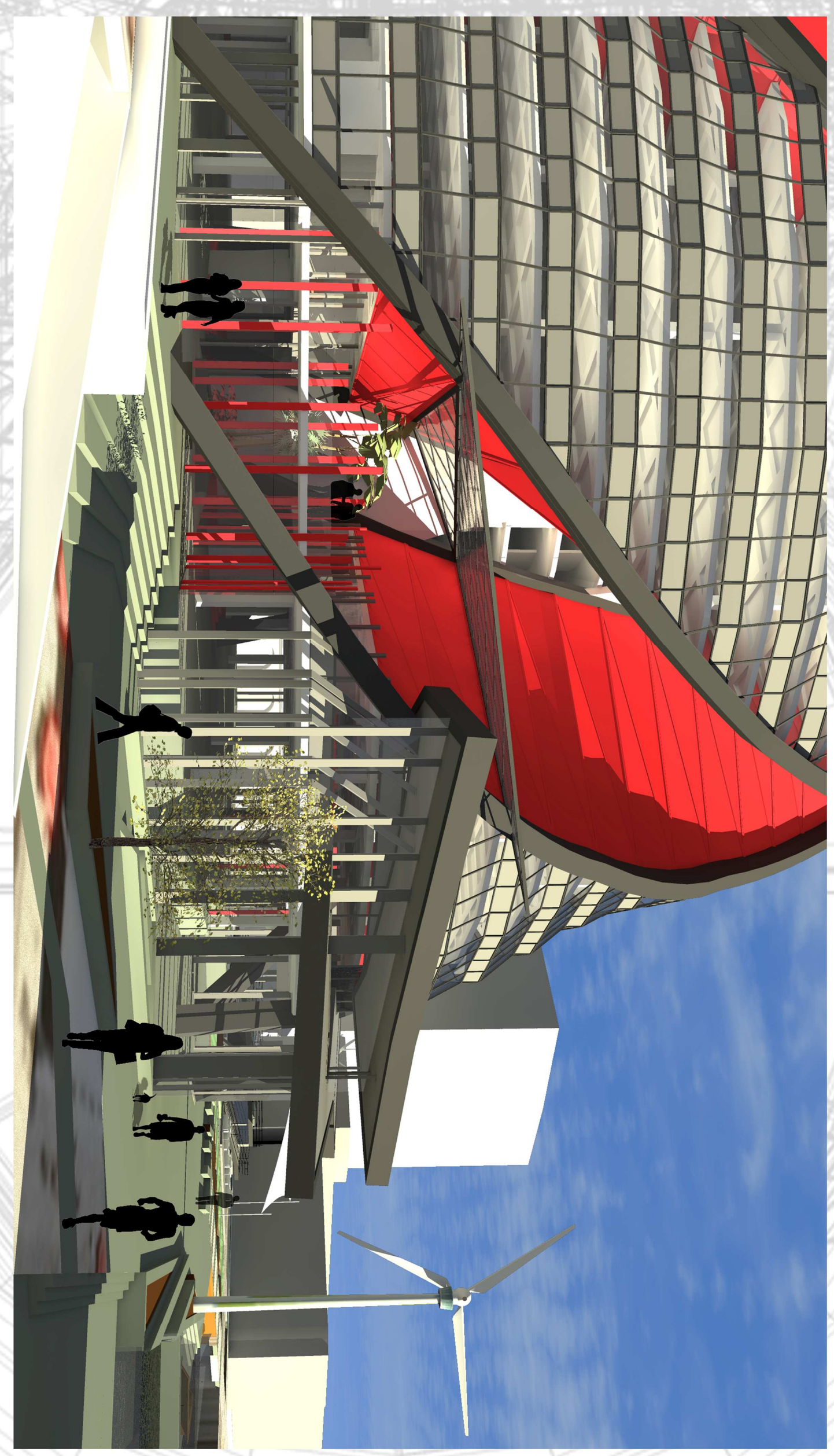

量 




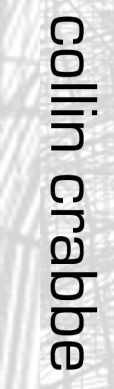
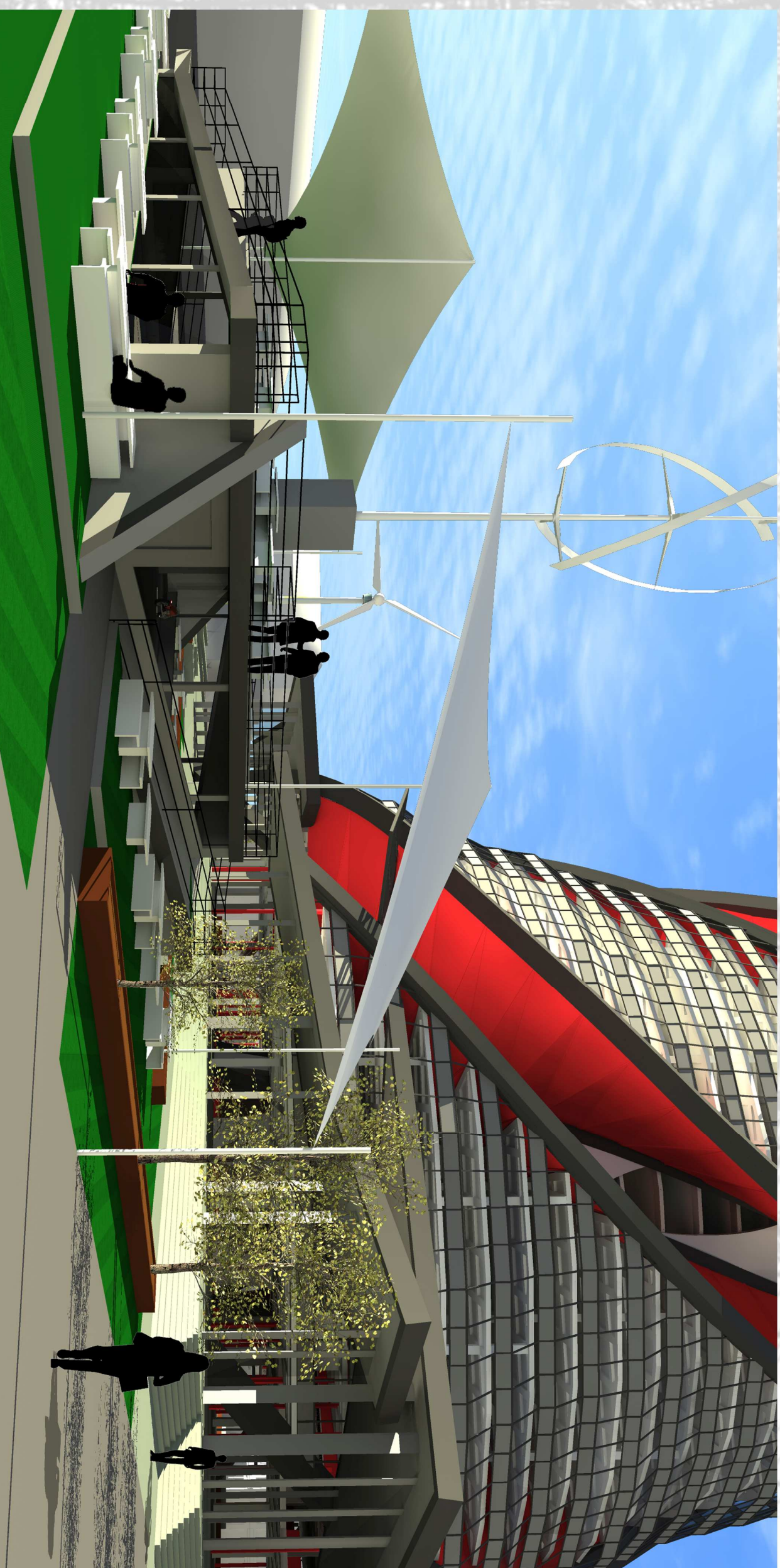

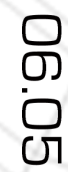




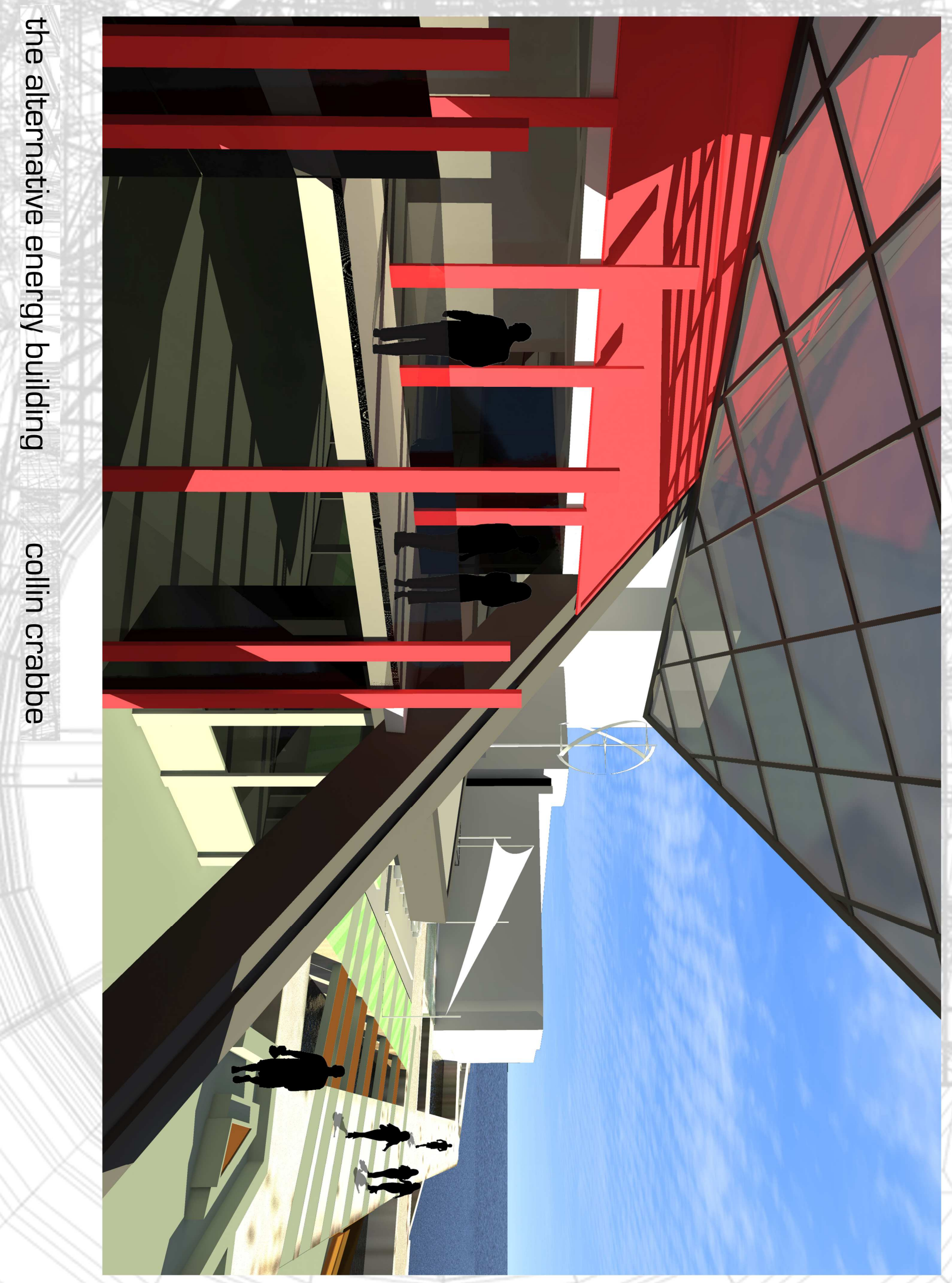

只 


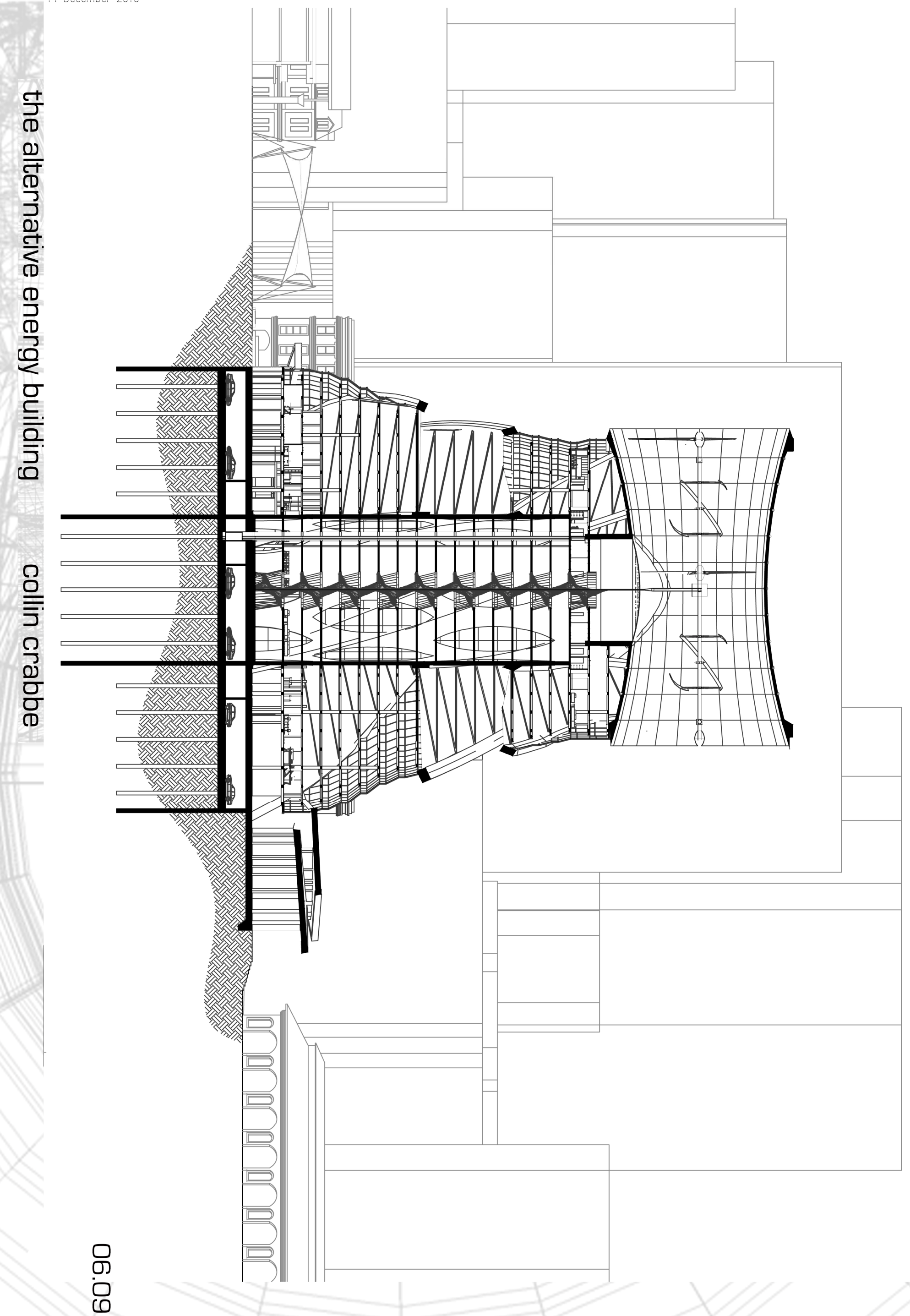

$\left[\begin{array}{l}L^{\circ} \\ \hline- \\ \hline\end{array}\right.$ 







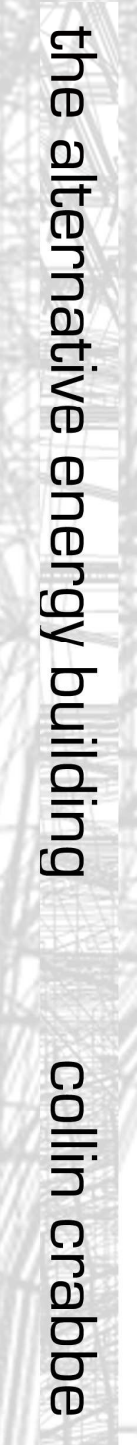

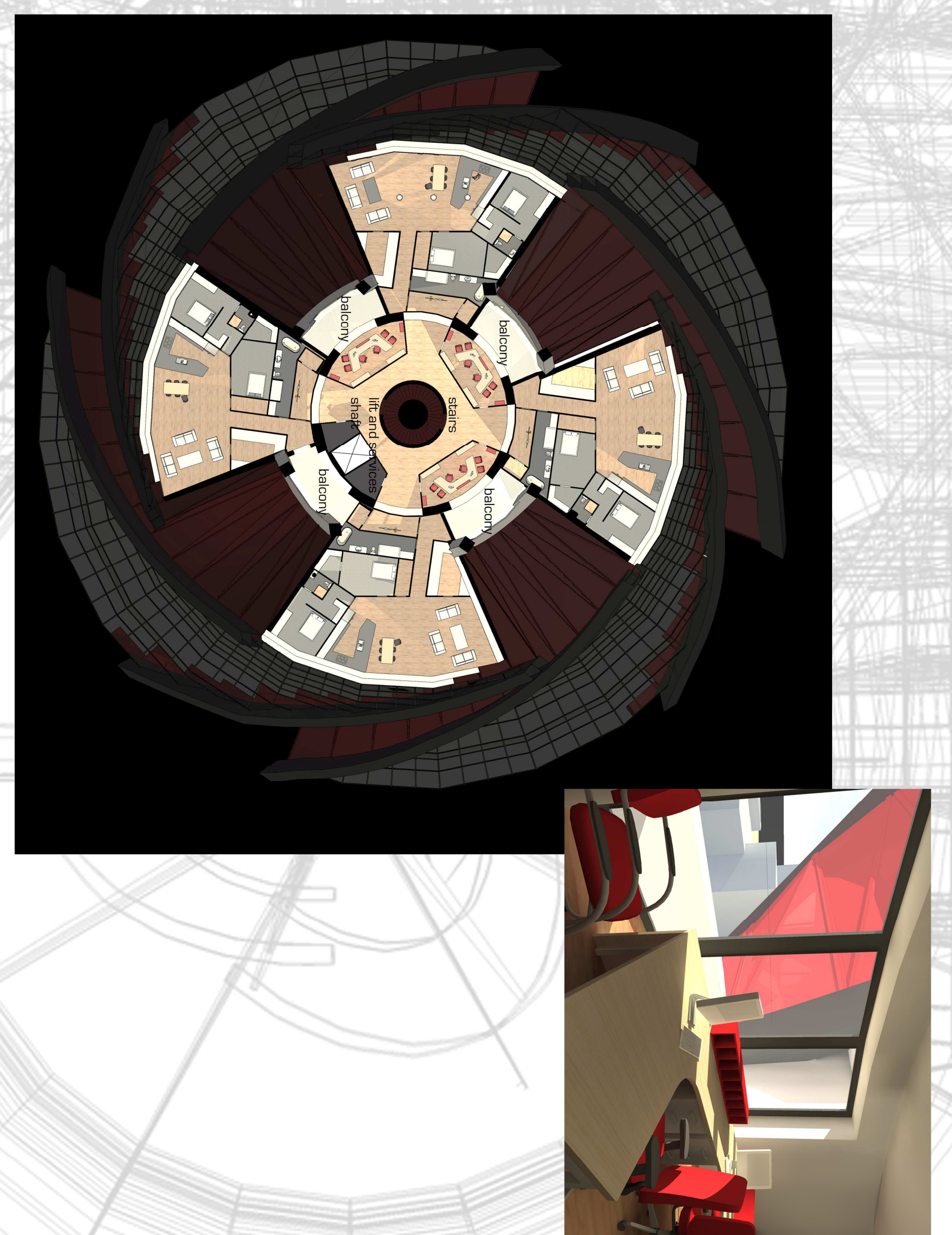






06.12

the alternative energy building collin crabbe 


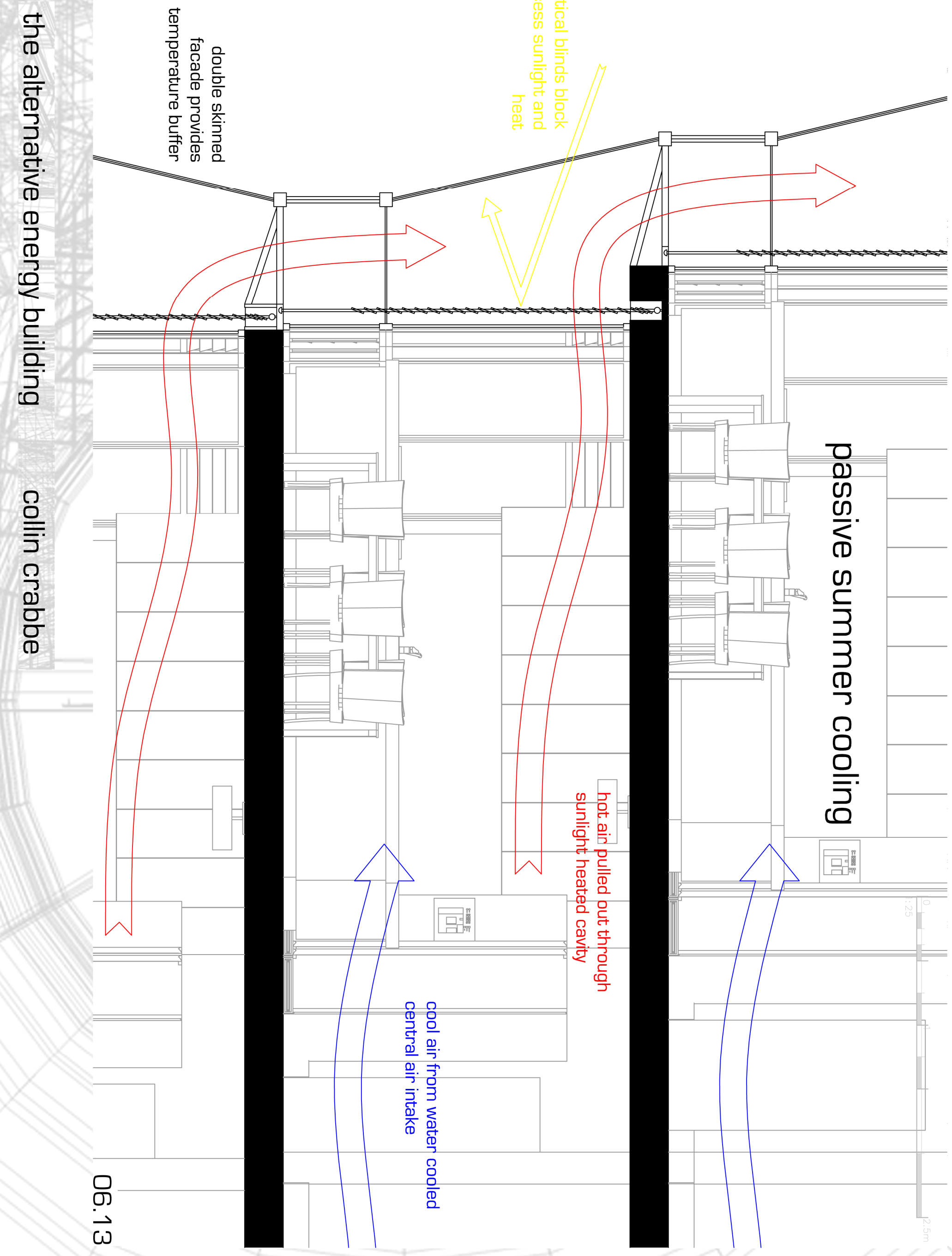




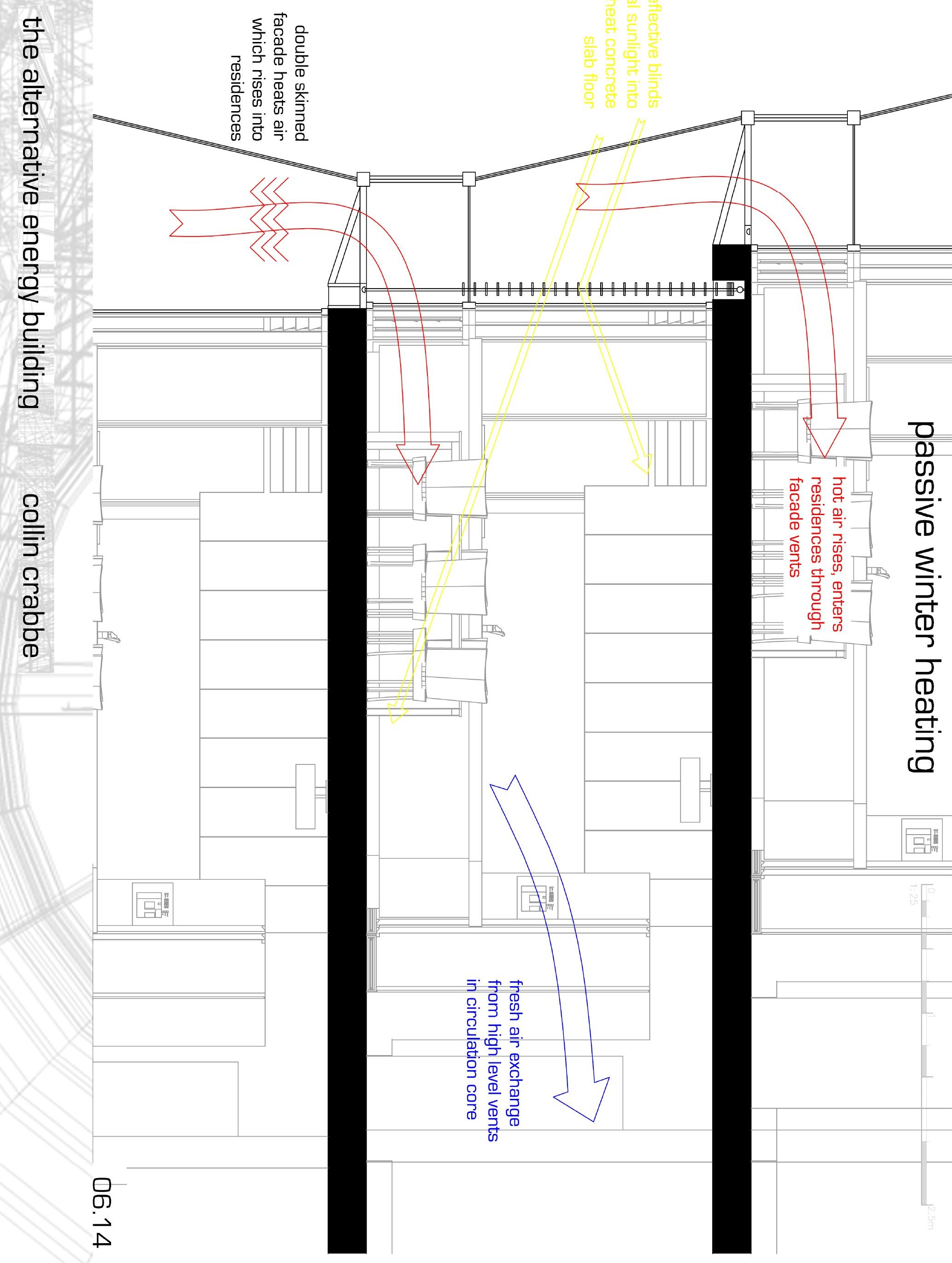






g
जे 


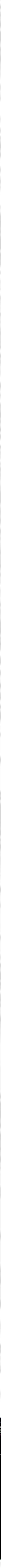

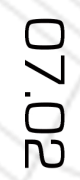









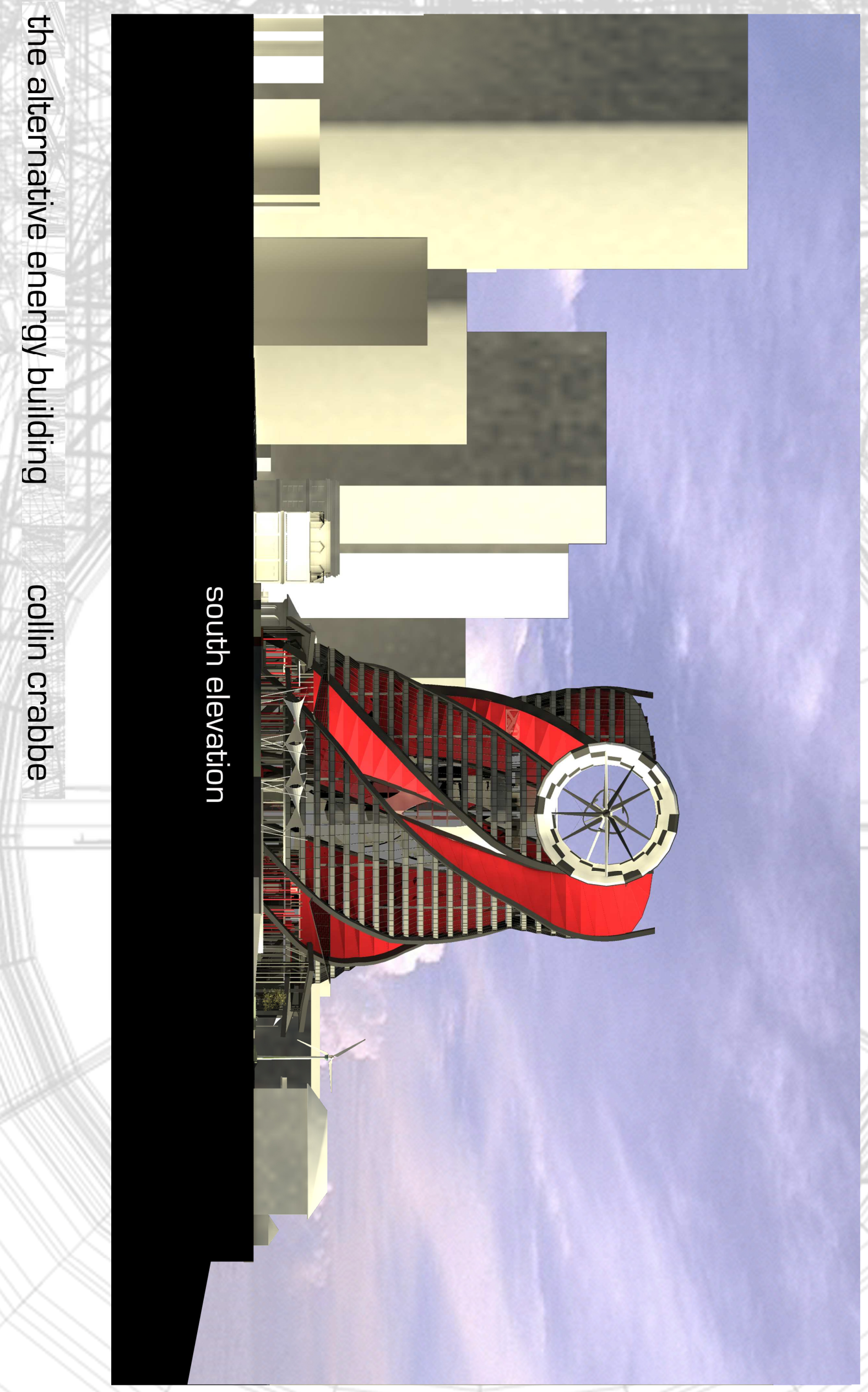

0
$\stackrel{0}{0}$
$\dot{\omega}$ 